\title{
New Method for Chloroamidation of Olefins. Application in the Synthesis of N- Glycopeptides and Anticancer Agents
}

\author{
Girish K. Rawal, Amit Kumar, Urmila Tawar, Yashwant D. Vankar \\ Department of Chemistry, Indian Institute of Technology Kanpur 208 016, India
}

Fax: 0091-512-259 0007; E mail: vankar@iitk.ac.in

\section{CONTENTS}

Copies of ${ }^{1} \mathrm{H}$ and ${ }^{13} \mathrm{C}$ NMR spectra of compounds $\mathbf{6}-\mathbf{1 0}$

Copies of nOe spectra of compound $\mathbf{1 0}$

Copies of ${ }^{1} \mathrm{H}$ and ${ }^{13} \mathrm{C}$ NMR spectra of compound 12

Copies of COSY and nOe spectra of compound 12

Copies of ${ }^{1} \mathrm{H}$ and ${ }^{13} \mathrm{C}$ NMR spectra of compound $\mathbf{1 3}$

Copies of COSY and nOe spectra of compound $\mathbf{1 3}$

Copies of ${ }^{1} \mathrm{H}$ and ${ }^{13} \mathrm{C}$ NMR spectra of compound $\mathbf{1 5}$

Copies of COSY spectra of compound 15

Copies of ${ }^{1} \mathrm{H}$ and ${ }^{13} \mathrm{C}$ NMR spectra of compound $\mathbf{1 6}$

Copies of ${ }^{1} \mathrm{H}$ and ${ }^{13} \mathrm{C}$ NMR spectra of compound $\mathbf{1 8}$

Copies of nOe spectra of compound $\mathbf{1 8}$

Copies of ${ }^{1} \mathrm{H}$ and ${ }^{13} \mathrm{C}$ NMR spectra of compound $\mathbf{1 9}$

Copy of COSY spectra of compound $\mathbf{1 9}$

Copies of ${ }^{1} \mathrm{H}$ and ${ }^{13} \mathrm{C}$ NMR spectra of compound 21

Copy of COSY of compound $\mathbf{2 1}$

Copies of ${ }^{1} \mathrm{H}$ and ${ }^{13} \mathrm{C}$ NMR spectra of compound 22

Copies of ${ }^{1} \mathrm{H}$ and ${ }^{13} \mathrm{C}$ NMR spectra of compound 24a

Copies of COSY and nOe spectra of compound $\mathbf{2 4 a}$

Copies of ${ }^{1} \mathrm{H}$ and ${ }^{13} \mathrm{C}$ NMR spectra of compound 24b
S3 - S8

S9

S10

$\mathrm{S} 11-\mathrm{S} 12$

$\mathrm{S} 13$

S14

S15

S16

S17

S18

S19

S20

S21

S22

S23

S24

S25

S26

S27 
Copies of COSY and nOe spectra of compound 24b $\quad$ S28

Copies of ${ }^{1} \mathrm{H}$ and ${ }^{13} \mathrm{C}$ NMR spectra of compound 24c S29

Copies of COSY and nOe spectra of compound 24c S30

Copies of ${ }^{1} \mathrm{H}$ and ${ }^{13} \mathrm{C}$ NMR spectra of compound $25 \quad$ S31

Copies of ${ }^{1} \mathrm{H}$ and ${ }^{13} \mathrm{C}$ NMR spectra of compound $26 \quad$ S32

Copies of COSY and nOe spectra of compound $26 \quad$ S33 - S34

Copies of ${ }^{1} \mathrm{H}$ and ${ }^{13} \mathrm{C}$ NMR spectra of compound $27 \quad \mathrm{~S} 35$

Copies of COSY and nOe spectra of compound $27 \quad$ S36 - S37

Copies of ${ }^{1} \mathrm{H}$ and ${ }^{13} \mathrm{C}$ NMR spectra of compound $28 \quad \mathrm{~S} 38$

Copies of COSY and nOe spectra of compound $28 \quad$ S39 - S41

Copies of 1H and 13C NMR spectra of compound $29 \quad$ S42

Copies of ${ }^{1} \mathrm{H}$ and ${ }^{13} \mathrm{C}$ NMR spectra of compound $30 \quad \mathrm{~S} 43$

Copies of ${ }^{1} \mathrm{H}$ and ${ }^{13} \mathrm{C}$ NMR spectra of compound 31

Copies of ${ }^{1} \mathrm{H}$ and ${ }^{13} \mathrm{C}$ NMR spectra of compound 32

Copies of ${ }^{1} \mathrm{H}$ and ${ }^{13} \mathrm{C}$ NMR spectra of compound $33 \quad \mathrm{~S} 46$

Copies of ${ }^{1} \mathrm{H}$ and ${ }^{13} \mathrm{C}$ NMR spectra of compound $34 \quad \mathrm{~S} 47$

Copies of ${ }^{1} \mathrm{H}$ and ${ }^{13} \mathrm{C}$ NMR spectra of compound $35 \quad \mathrm{~S} 48$

Copies of ${ }^{1} \mathrm{H}$ and ${ }^{13} \mathrm{C}$ NMR spectra of compound $36 \quad$ S53

Copies of ${ }^{1} \mathrm{H}$ and ${ }^{13} \mathrm{C}$ NMR spectra of compound $37 \quad \mathrm{~S} 54$ 


\section{Copy of 1H and 13C spectra for compound 6}
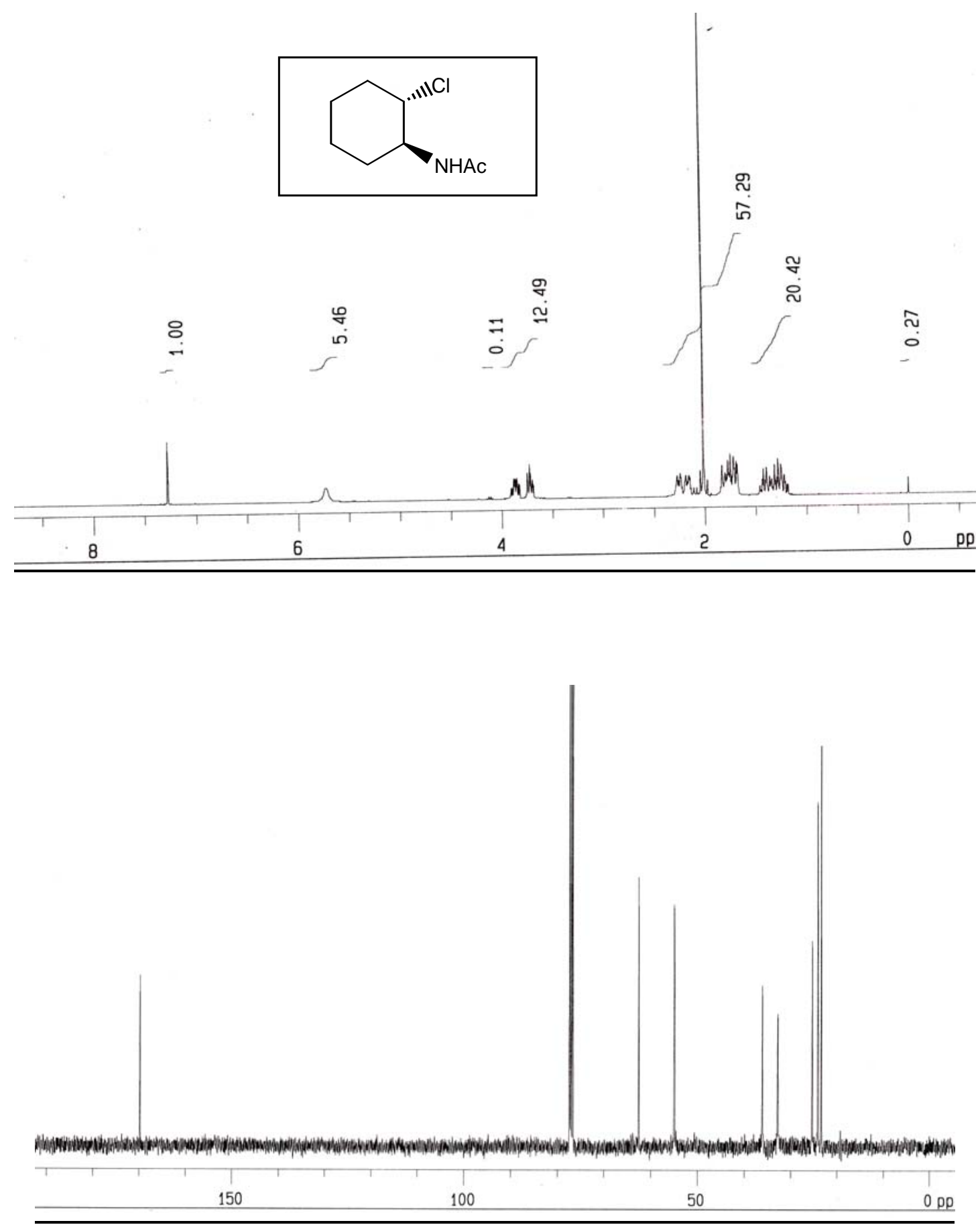


\section{Copy of 1H and 13C spectra for compound 7.}
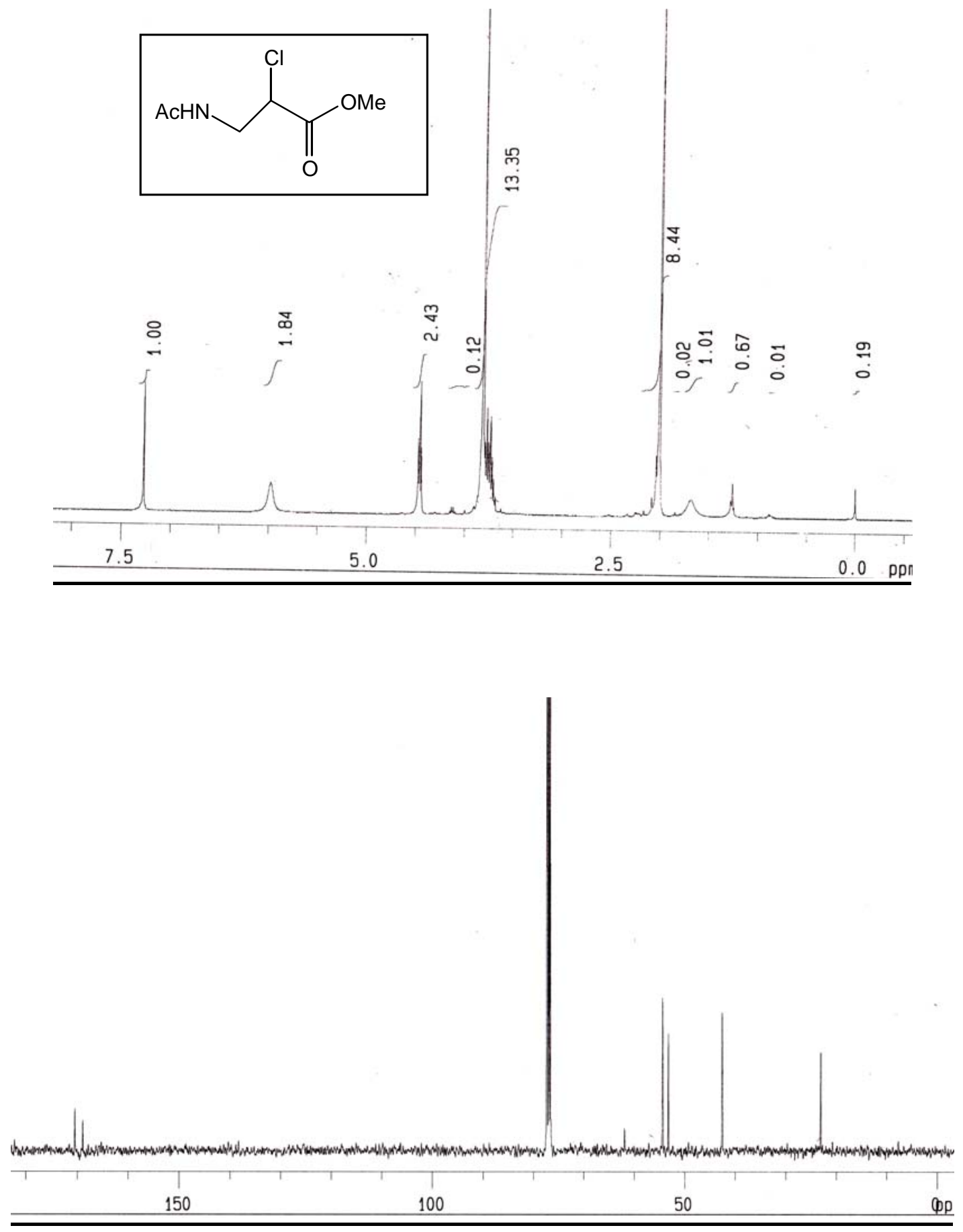
Copy of $1 \mathrm{H}$ and 13C spectra for compound 8.
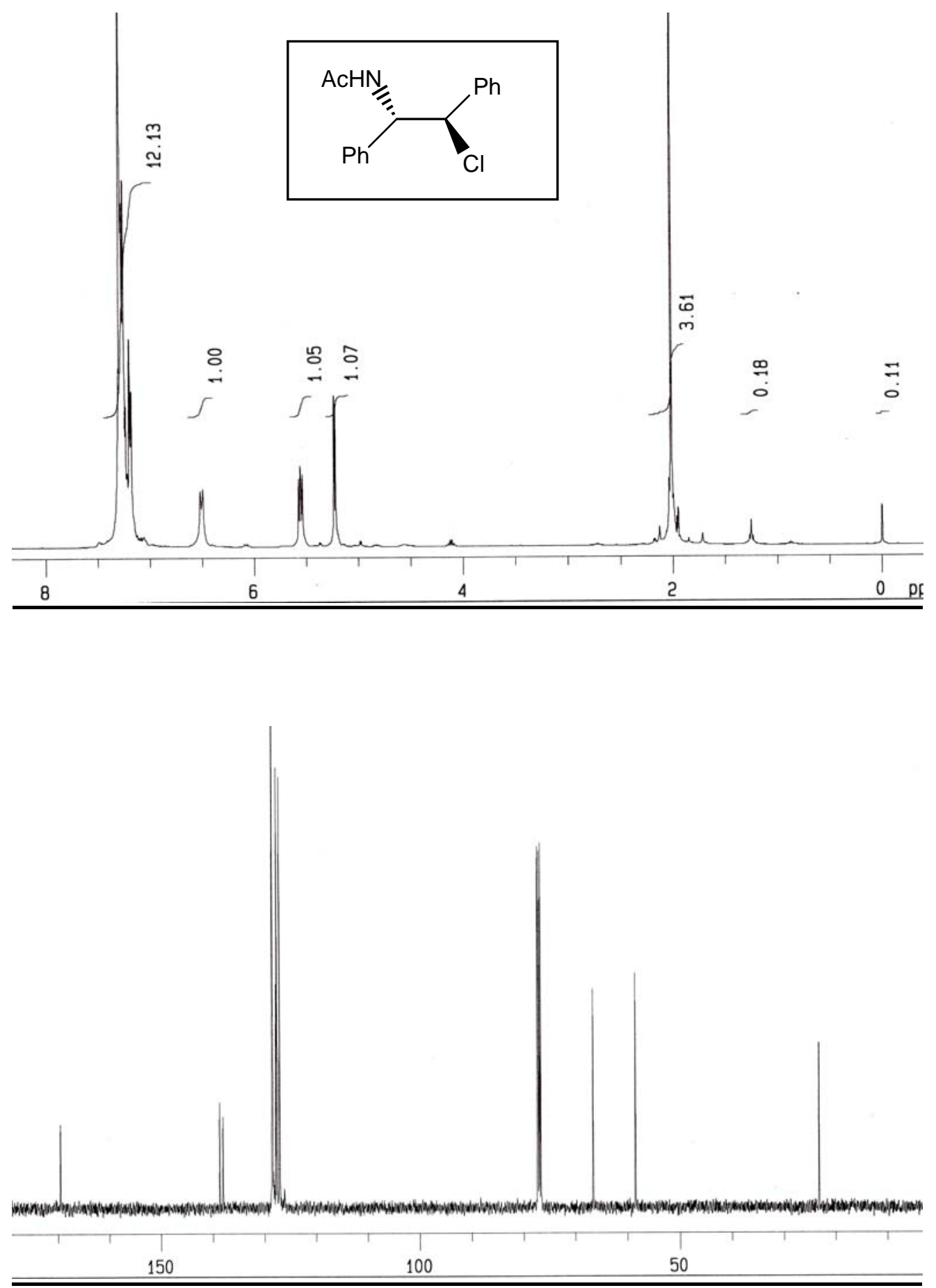
Copy of 1H and 13C spectra for compound 8a.
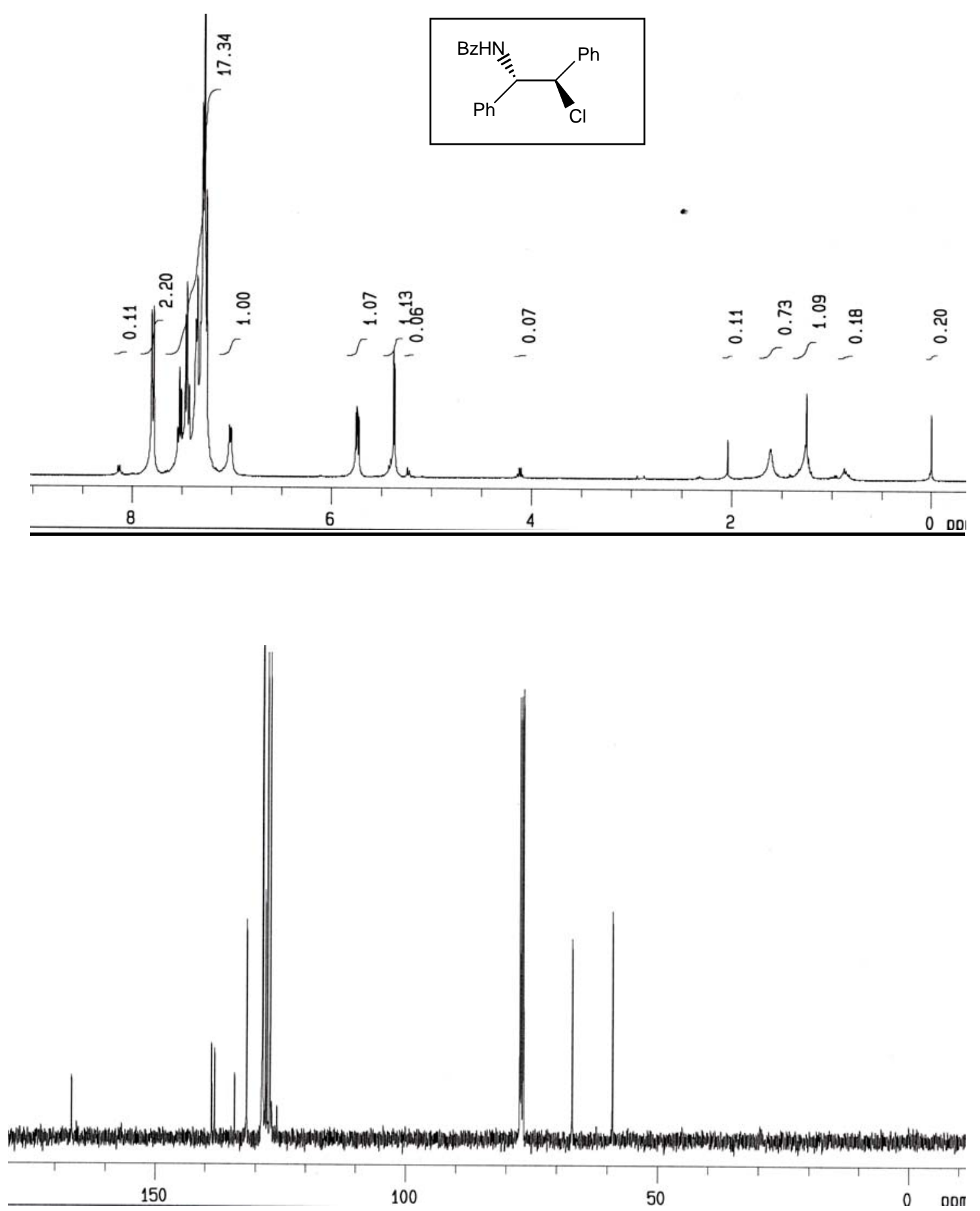


\section{Copy of 1H and 13C spectra for compound 9.}
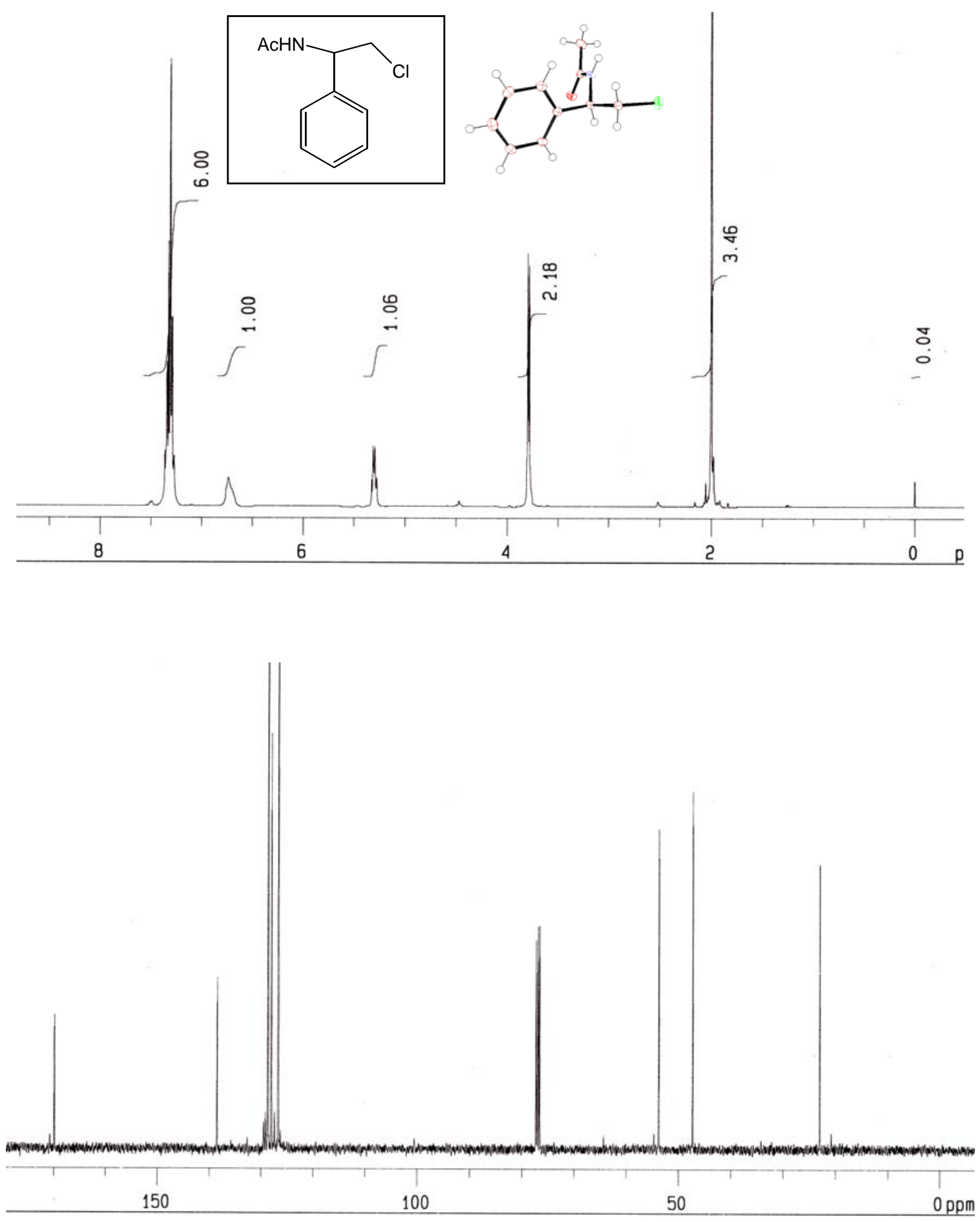
Copy of 1H and 13C spectra for compound 10.
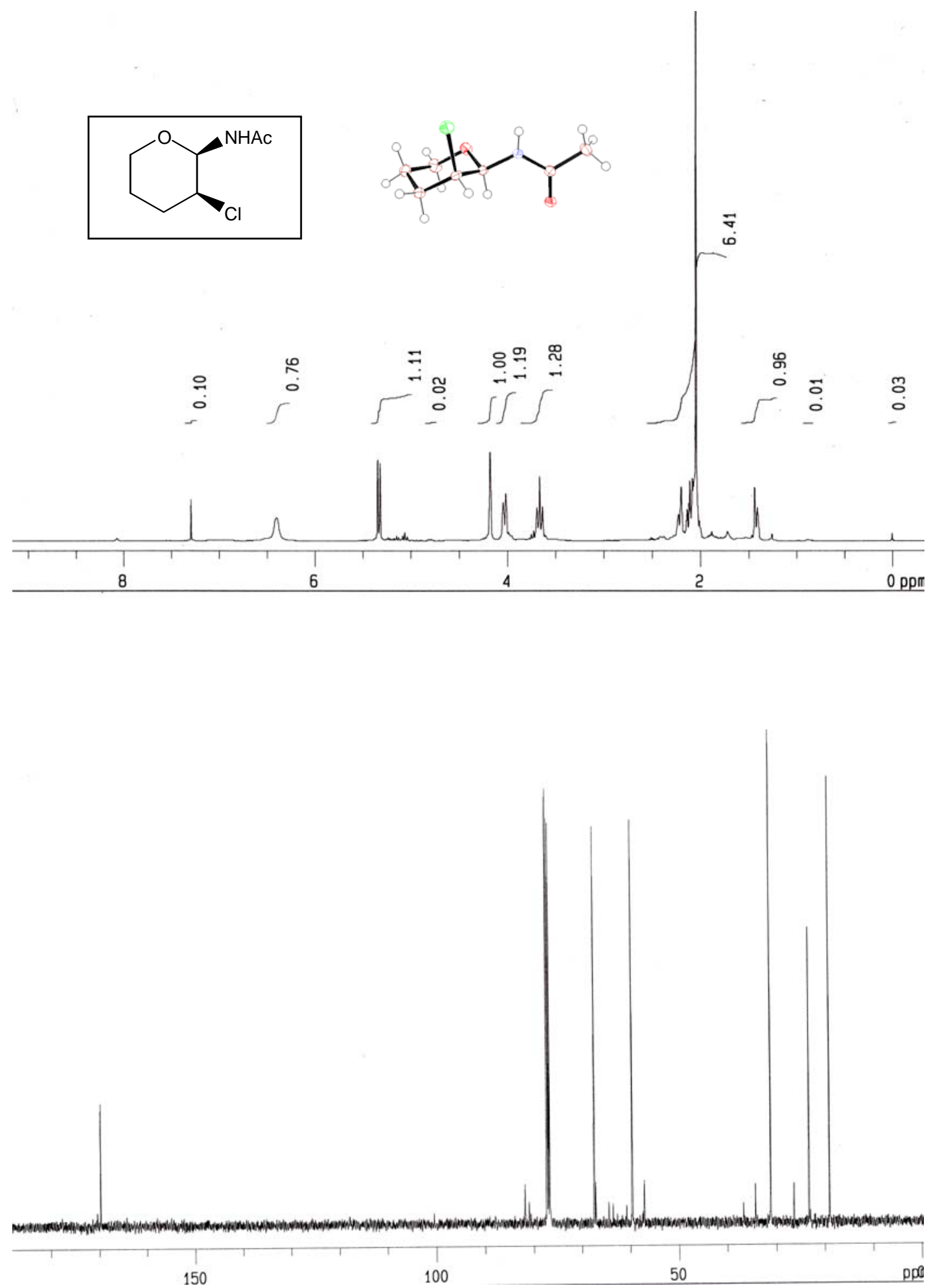
nOe spectra of compound 10.

nOe Irradiation of $\mathrm{H}-1$ showing enhancement in $\mathrm{H}-2$

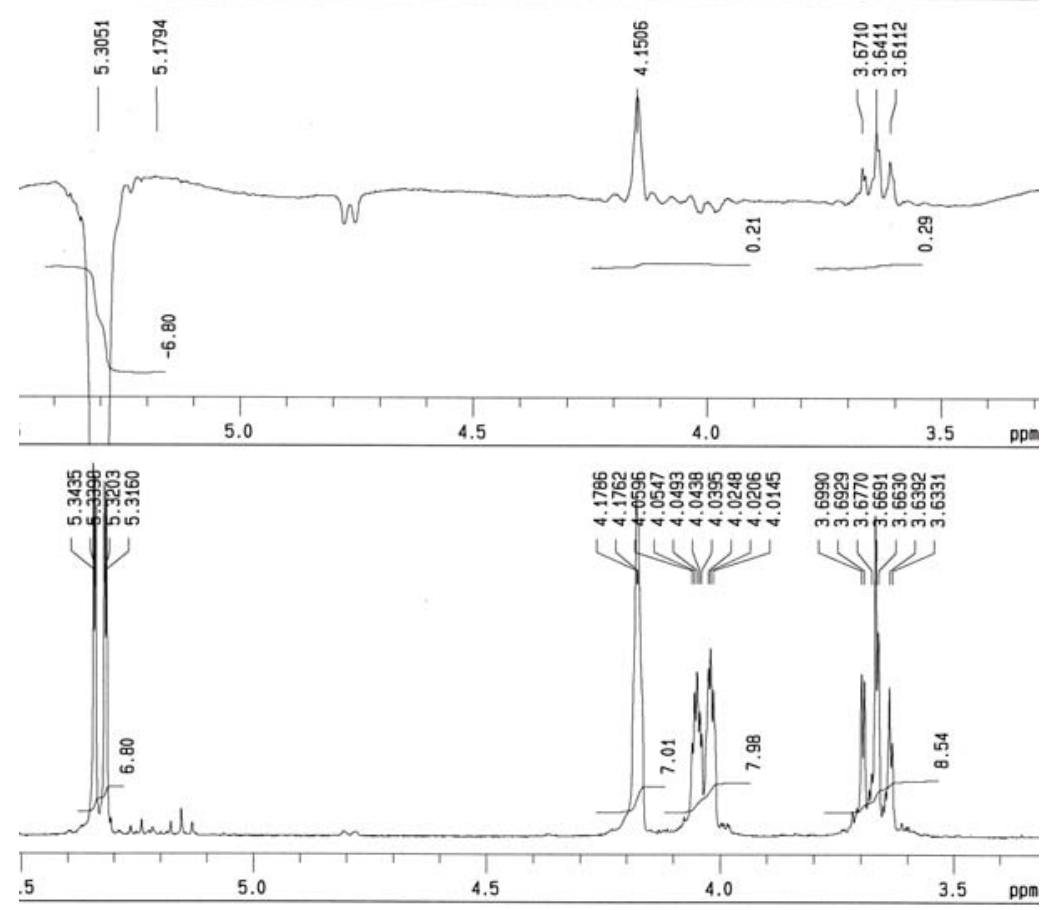

nOe Irradiation of $\mathrm{H}-2$ showing enhancement in $\mathrm{H}-1$

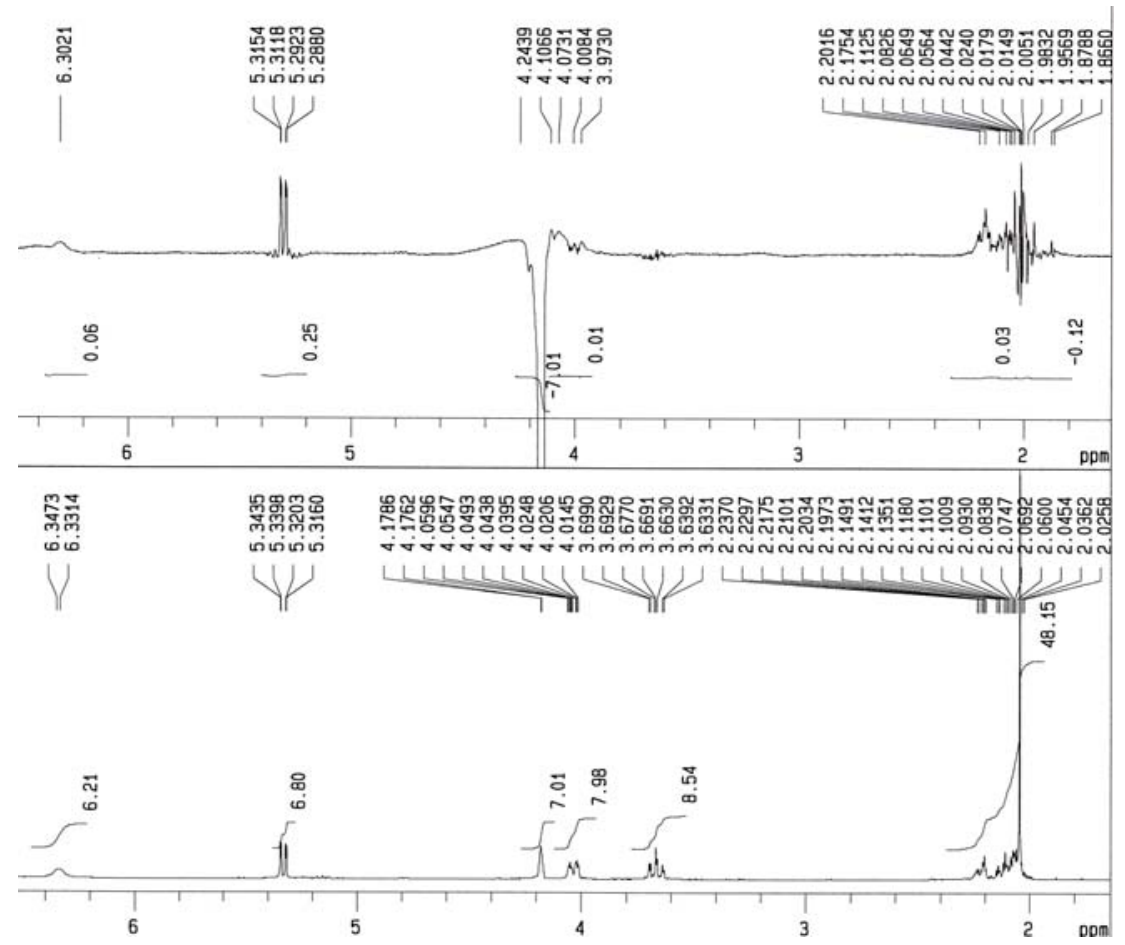




\section{Copy of 1H and 13C spectra for compound 12.}
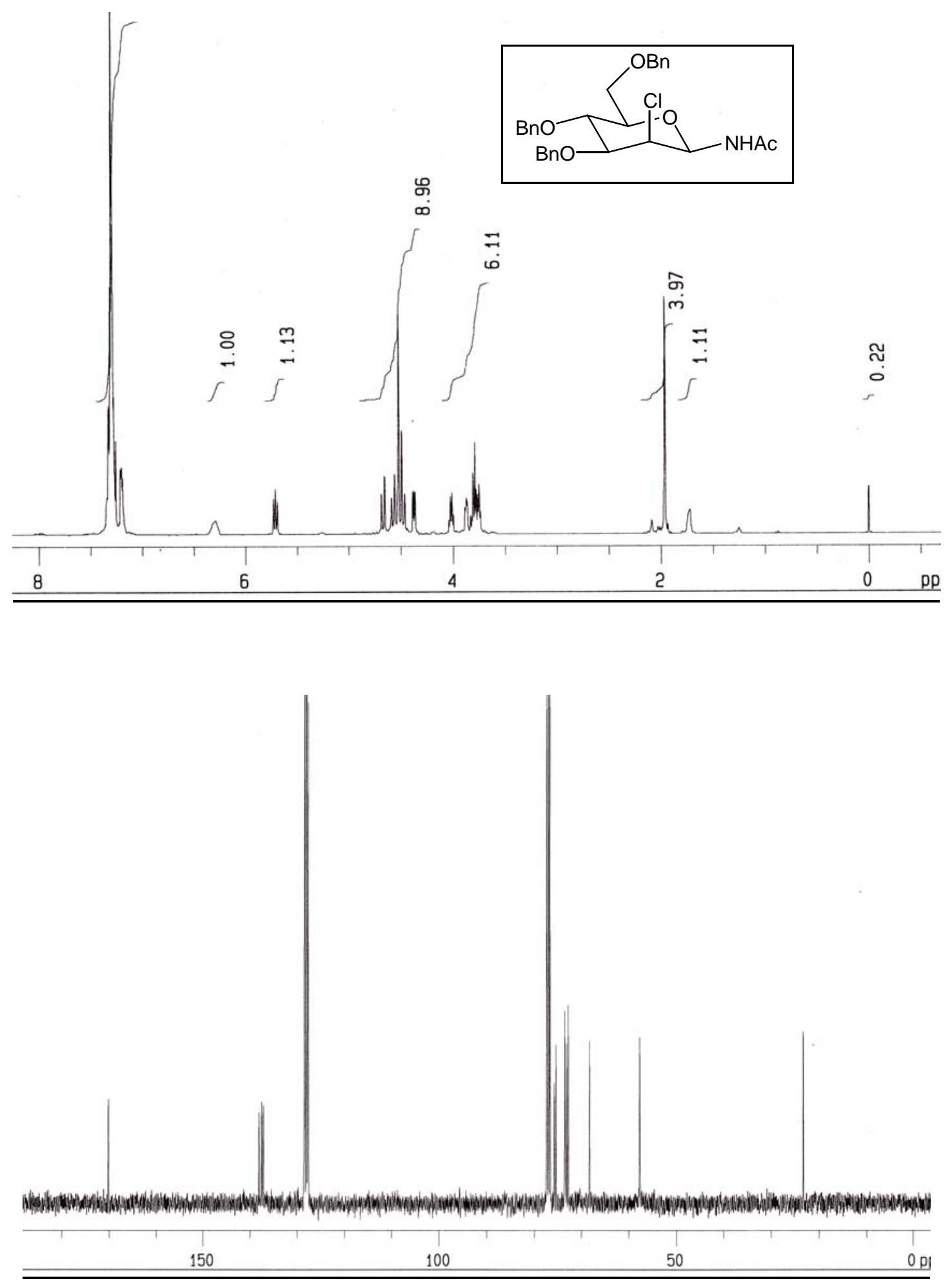
COSY and nOe spectra of Compound 12.

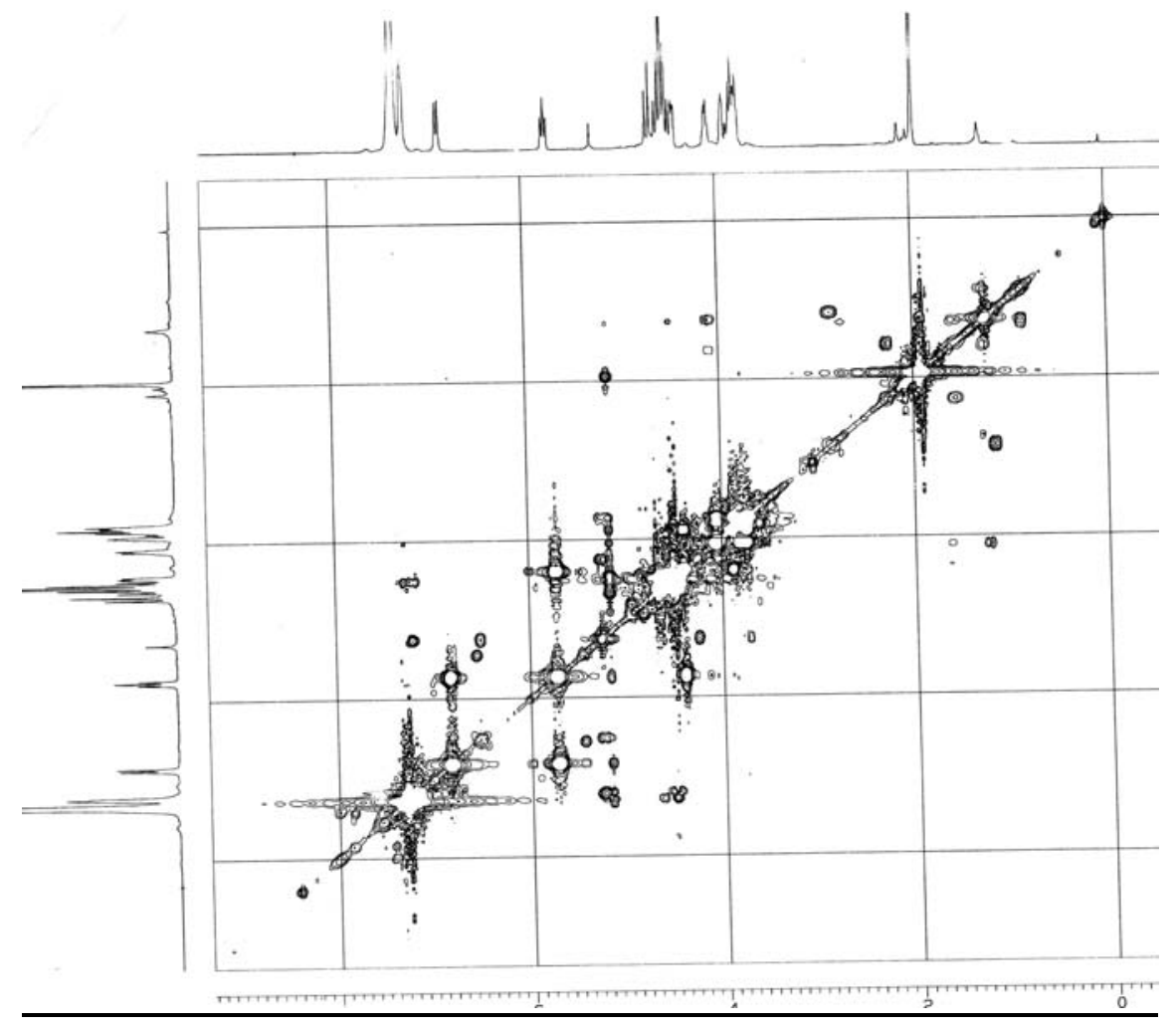

nOe Irradiation of $\mathrm{H}-1$ showing enhancement in $\mathrm{H}-2$ and $\mathrm{H}-5$

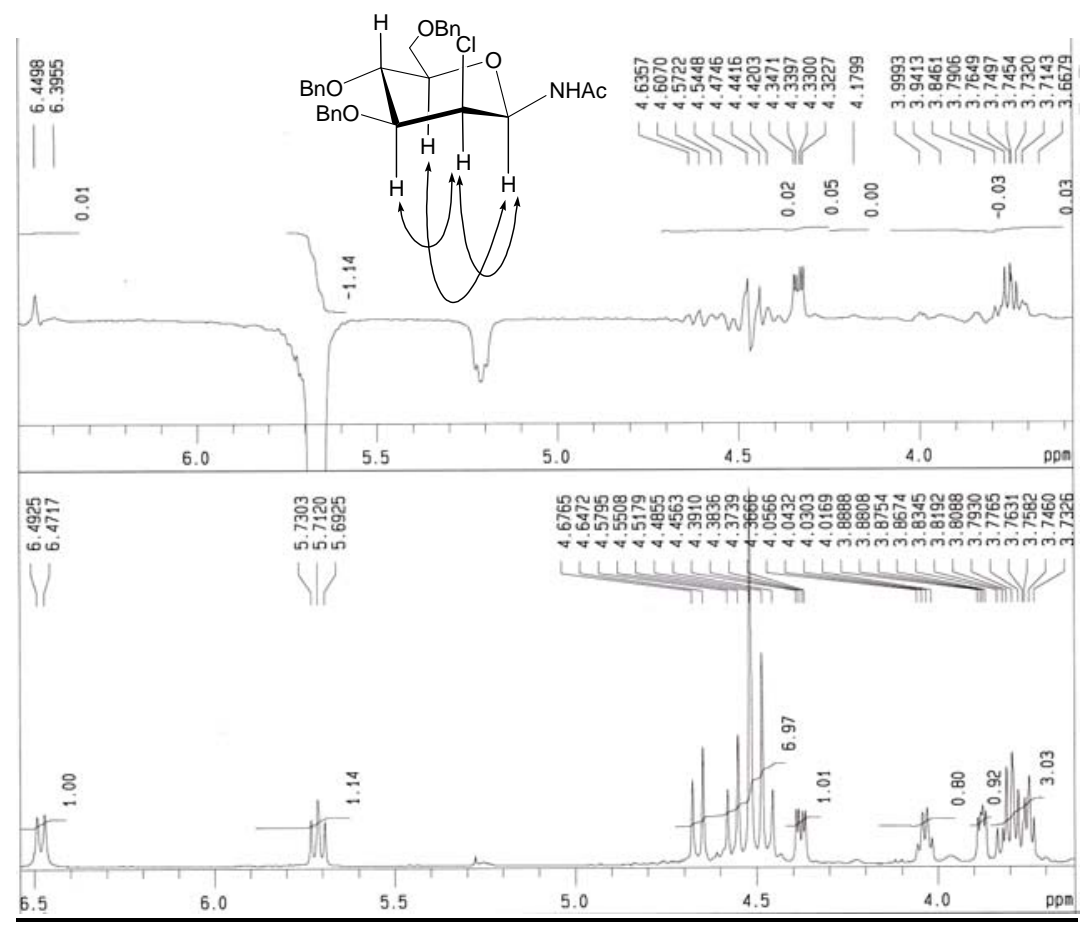


nOe Irradiation of $\mathrm{H}-2$ showing enhancement in $\mathrm{H}-1$ and $\mathrm{H}-3$

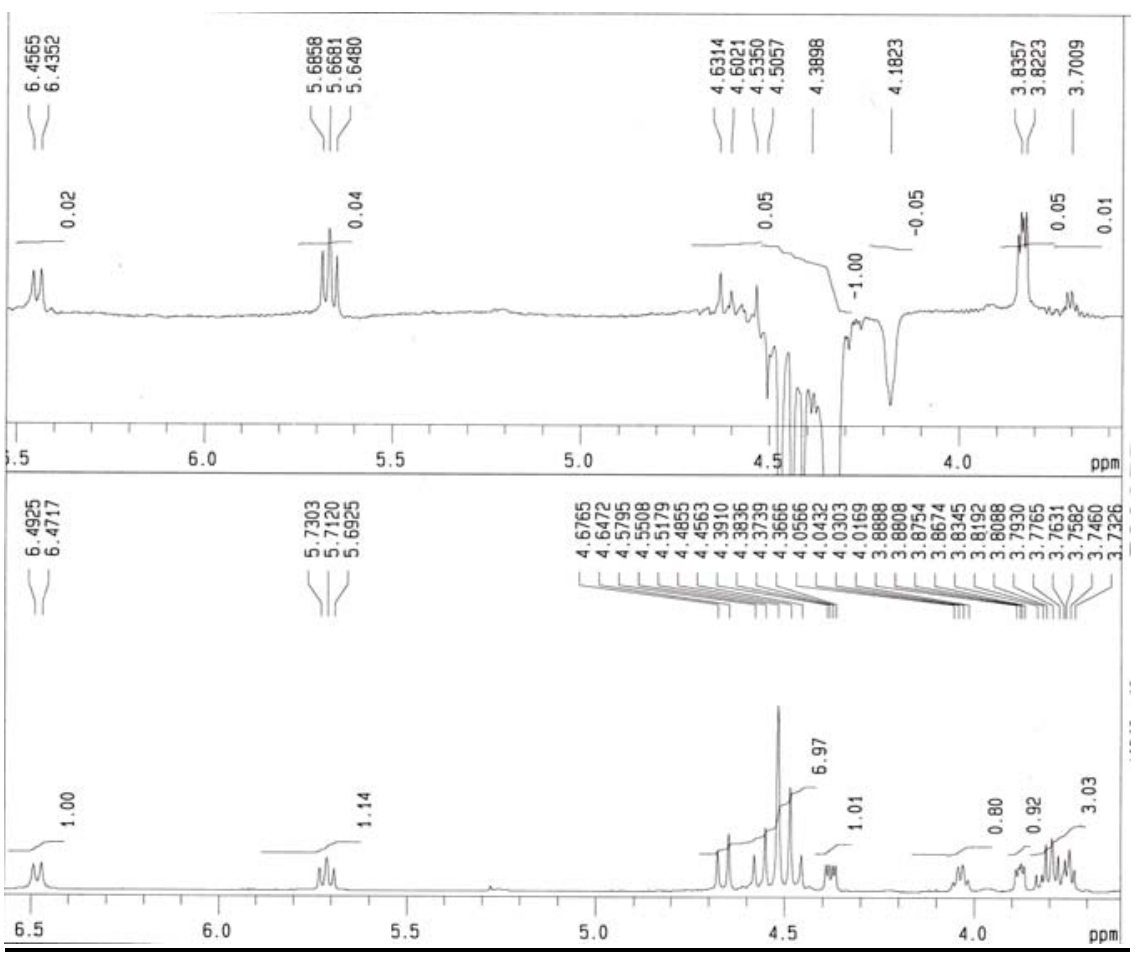

nOe Irradiation of $\mathrm{H}-3$ showing enhancement in $\mathrm{H}-1$ and $\mathrm{H}-2$

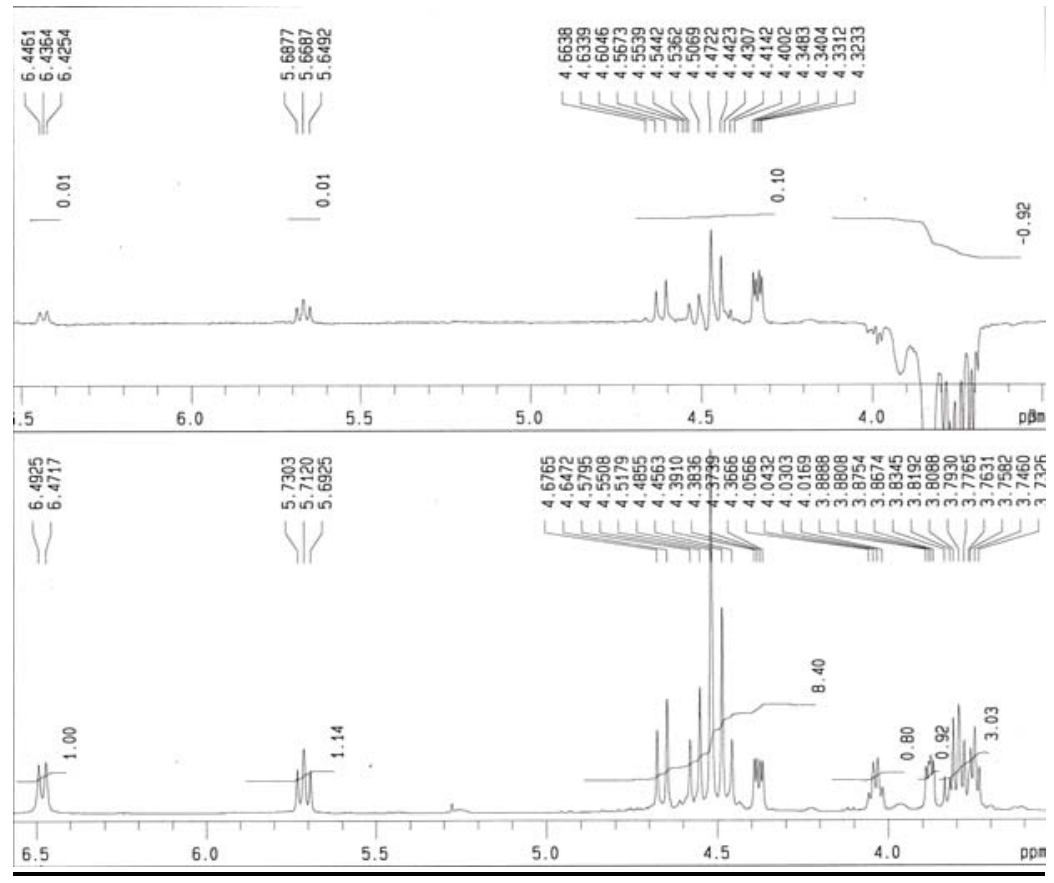


Copy of $1 \mathrm{H}$ and 13C spectra for compound 13.
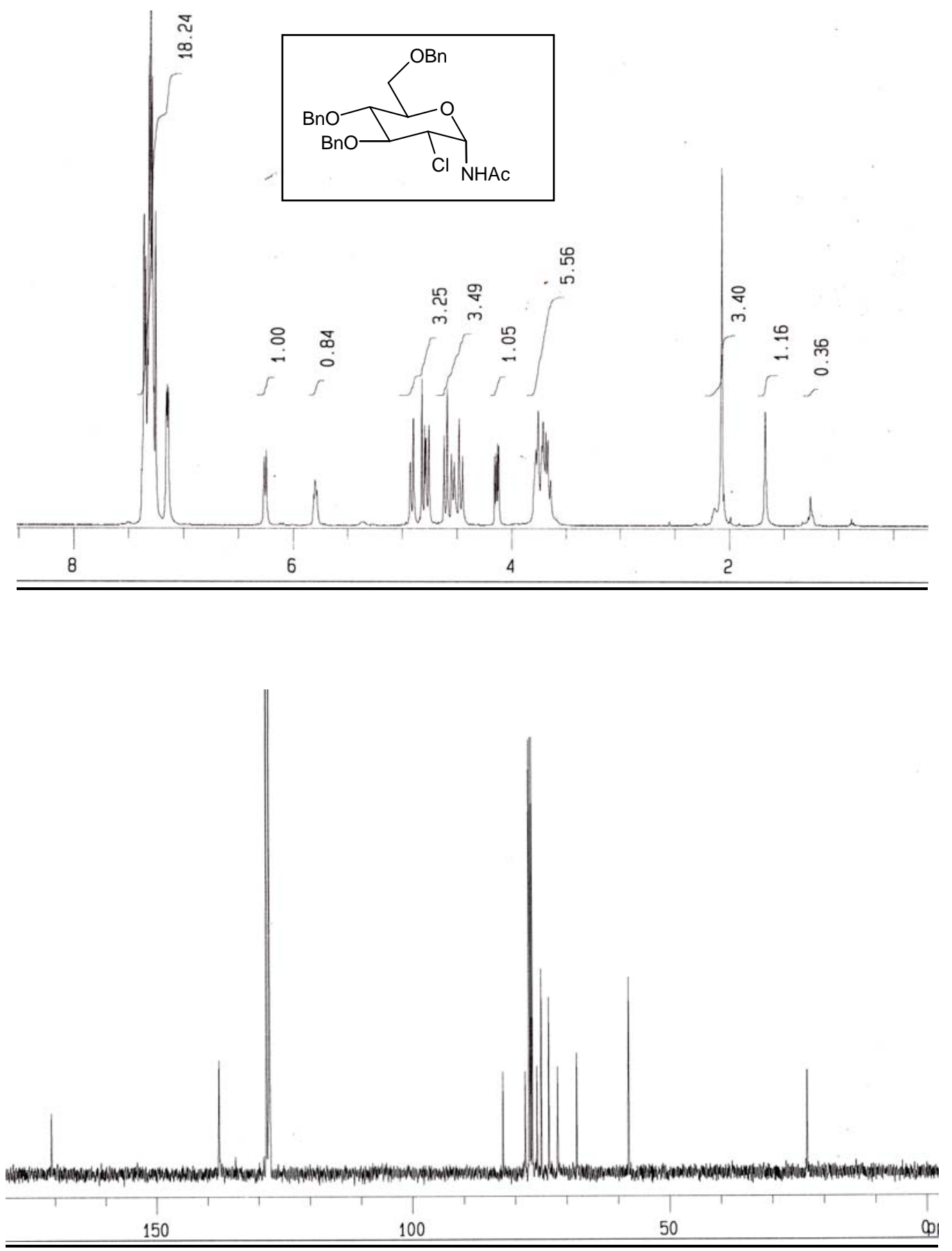
COSY and nOe spectra of compound 13.

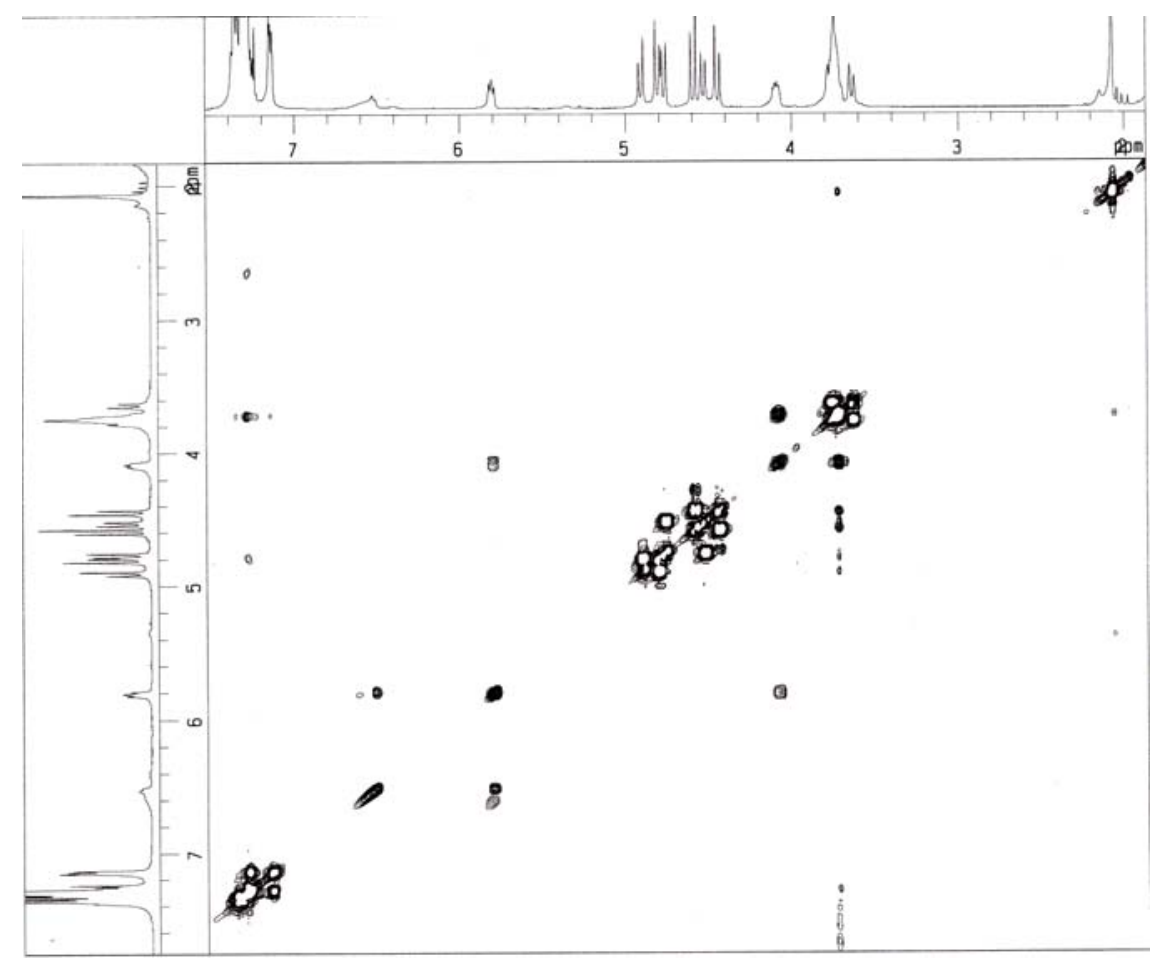

nOe Irradiation of $\mathrm{H}-1$ showing enhancement only in $\mathrm{H}-2$

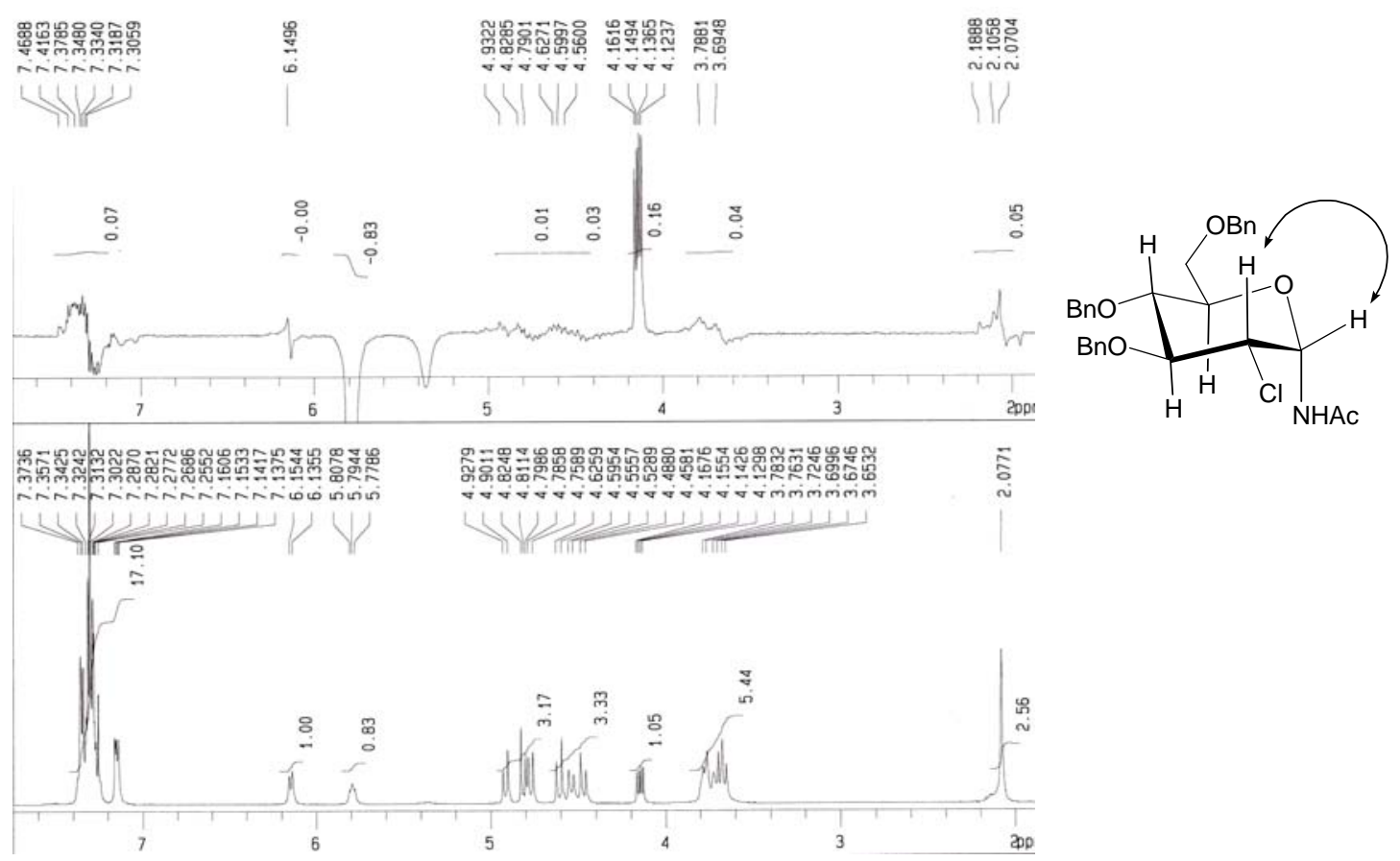


Copy of $1 \mathrm{H}$ and 13C spectra for compound 15.
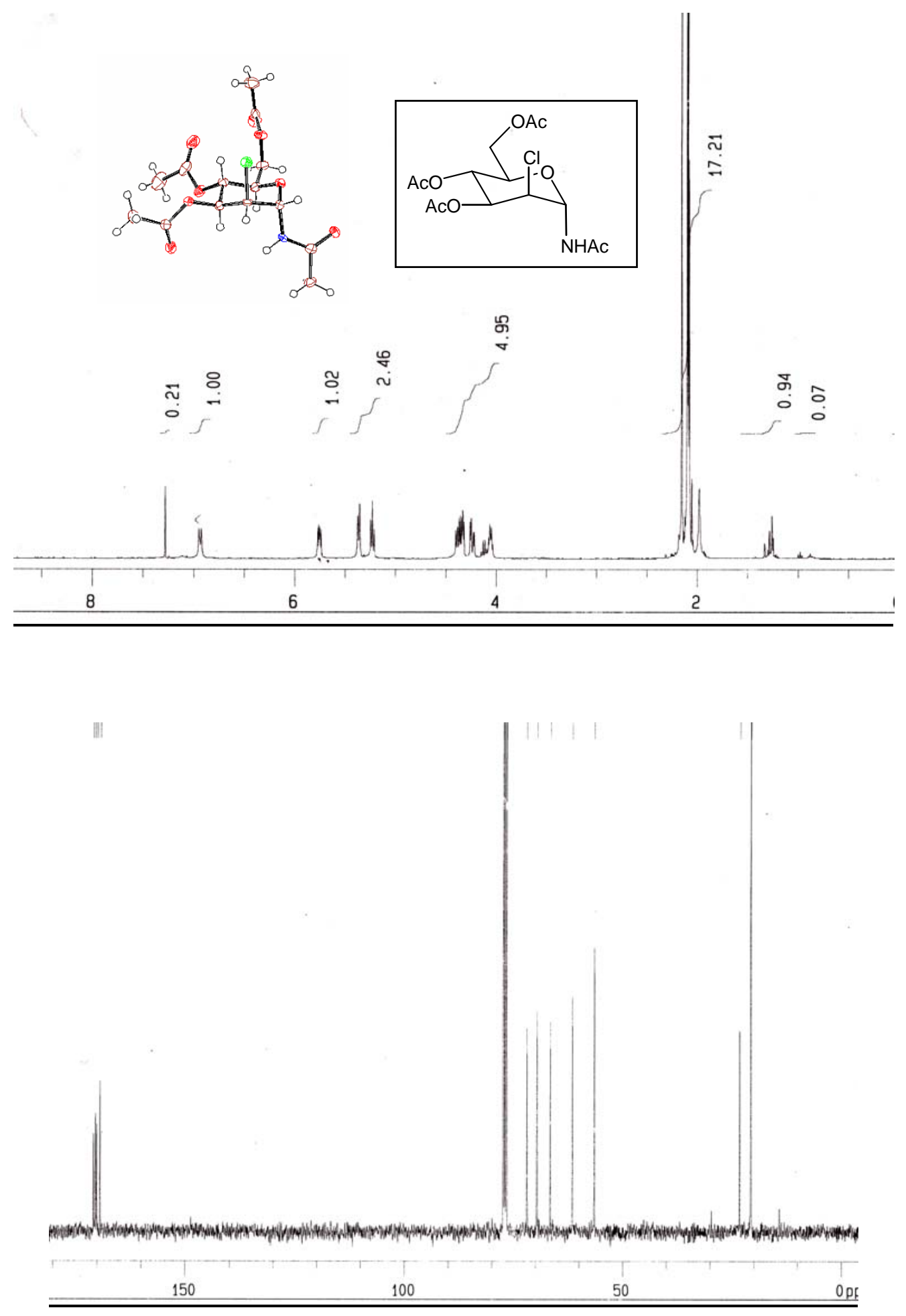
COSY spectra of compound 15.

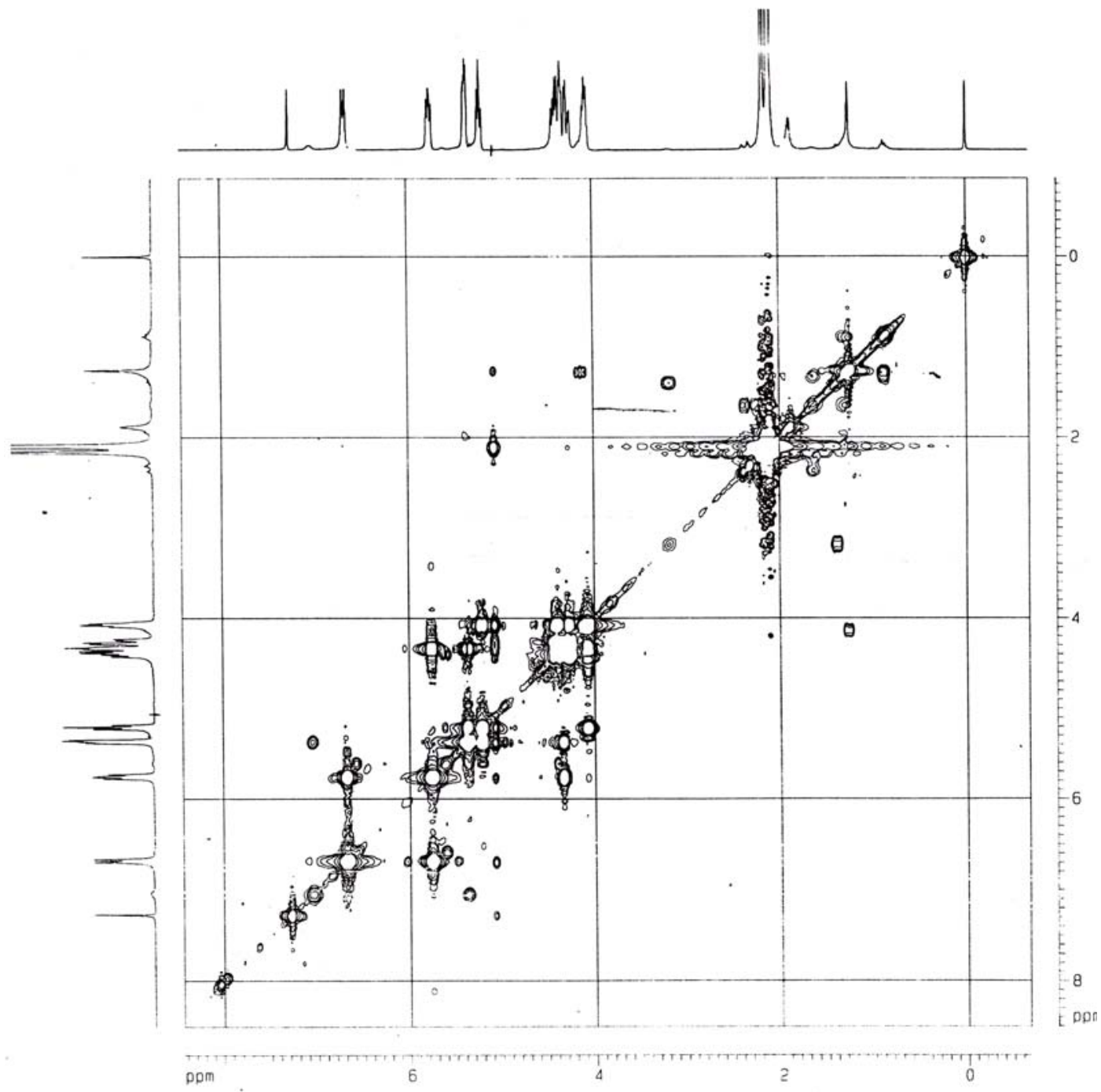




\section{Copy of 1H and 13C spectra for compound 16.}
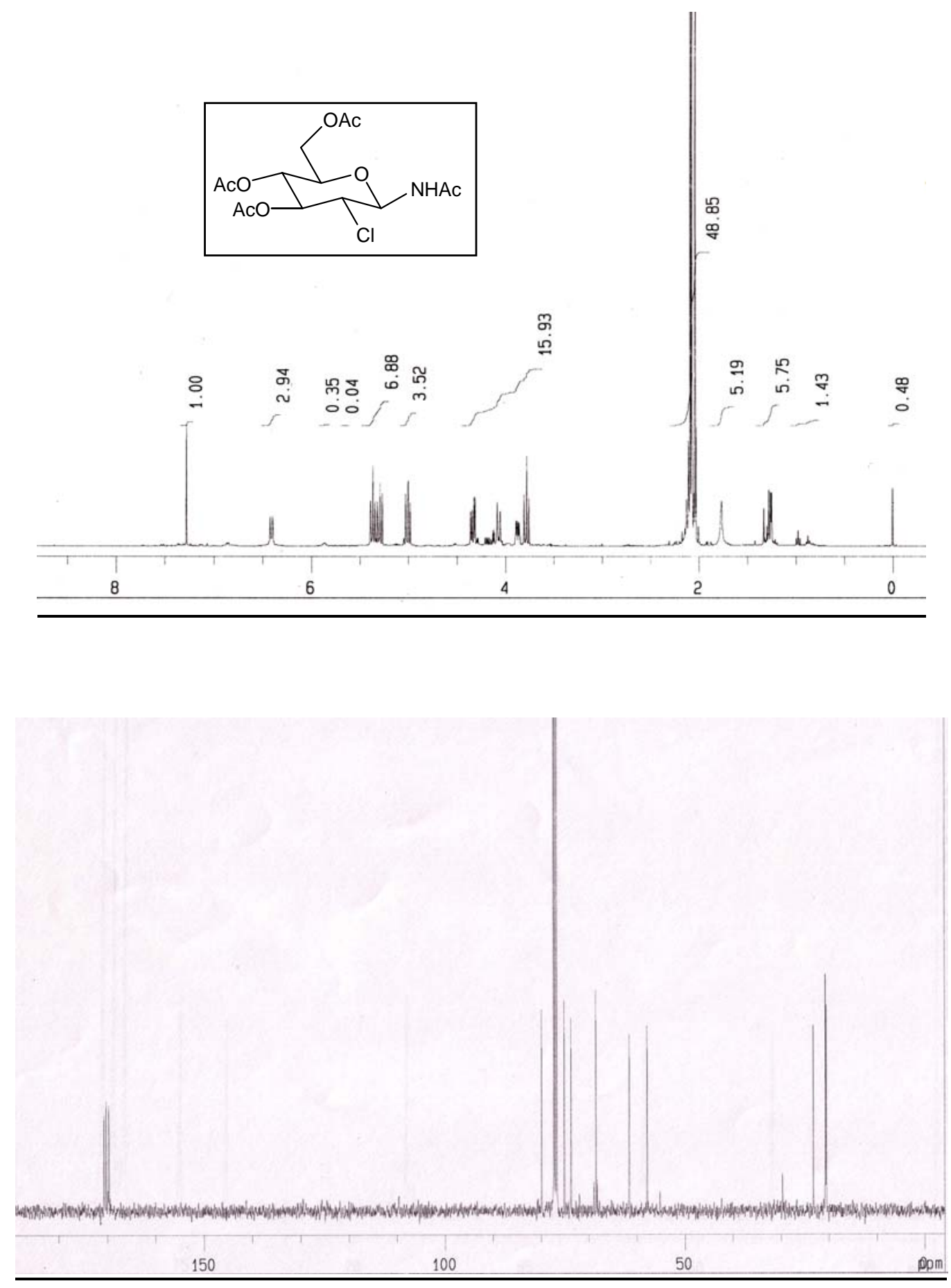
Copy of $1 \mathrm{H}$ and 13C spectra for compound 18.
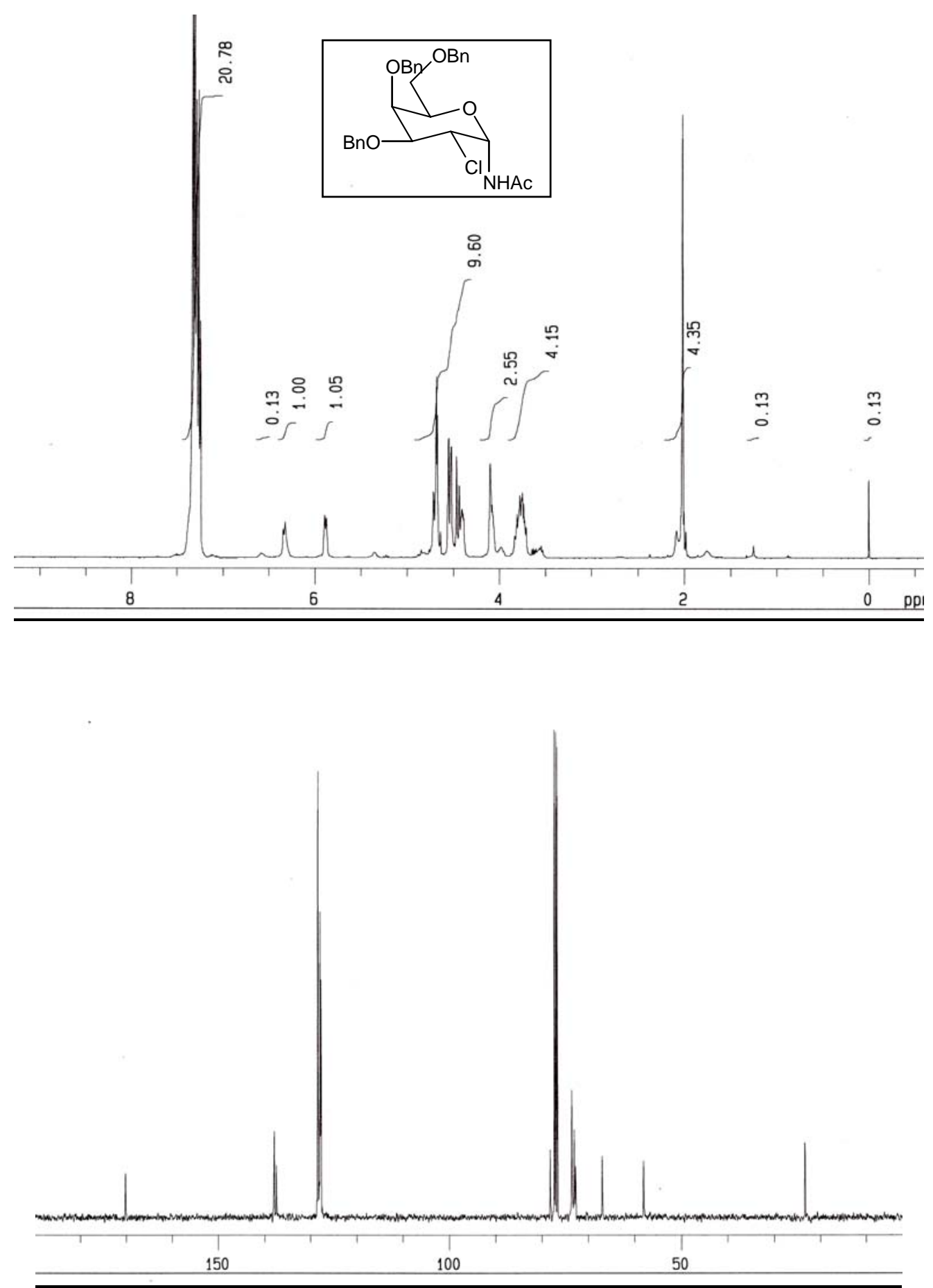
nOe spectra of compound 18.

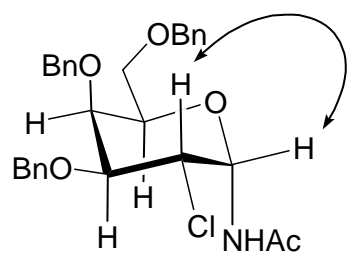

nOe Irradiation of $\mathrm{H}-1$ showing enhancement only in $\mathrm{H}-2$

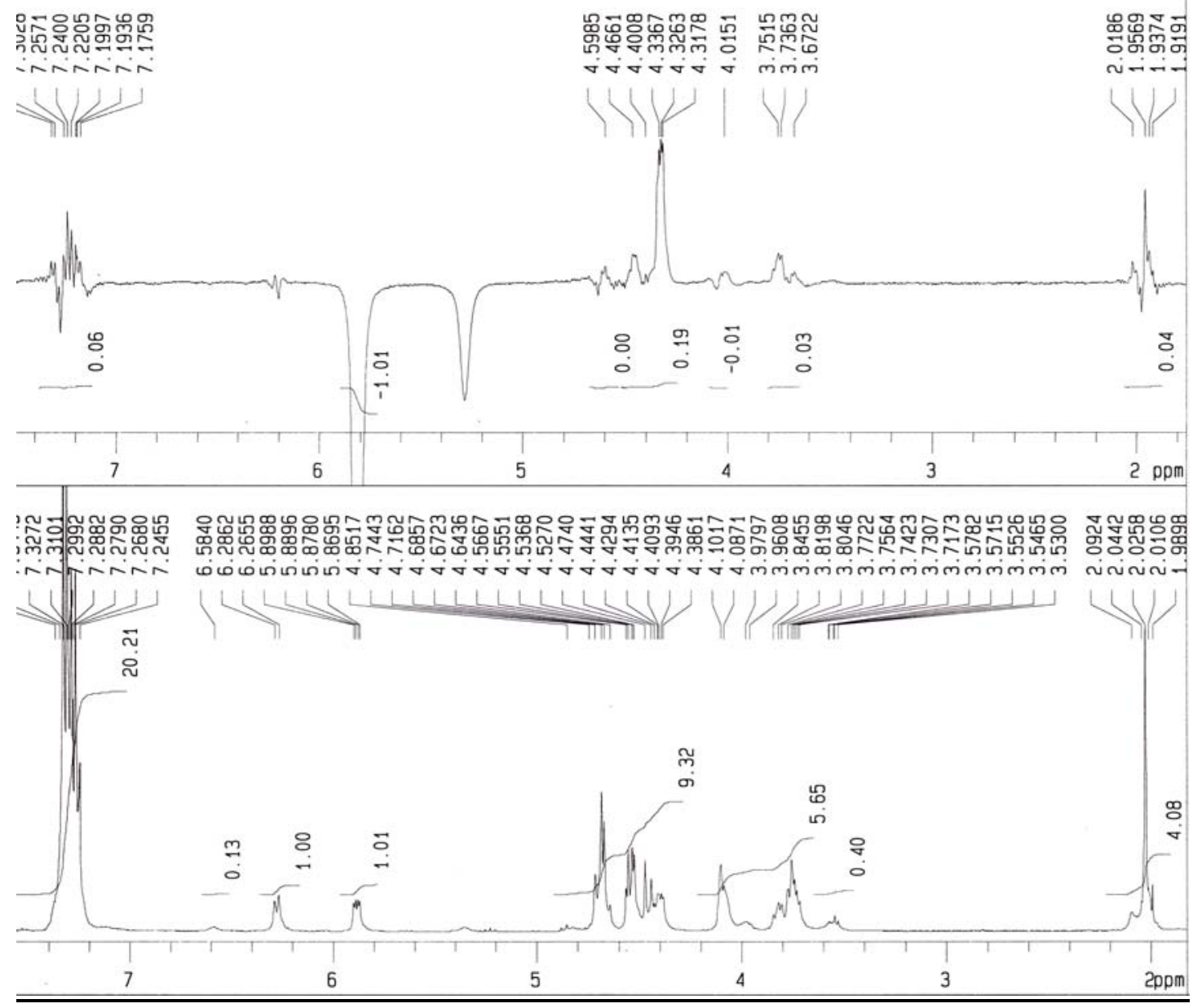




\section{Copy of 1H and 13C spectra for compound 19.}
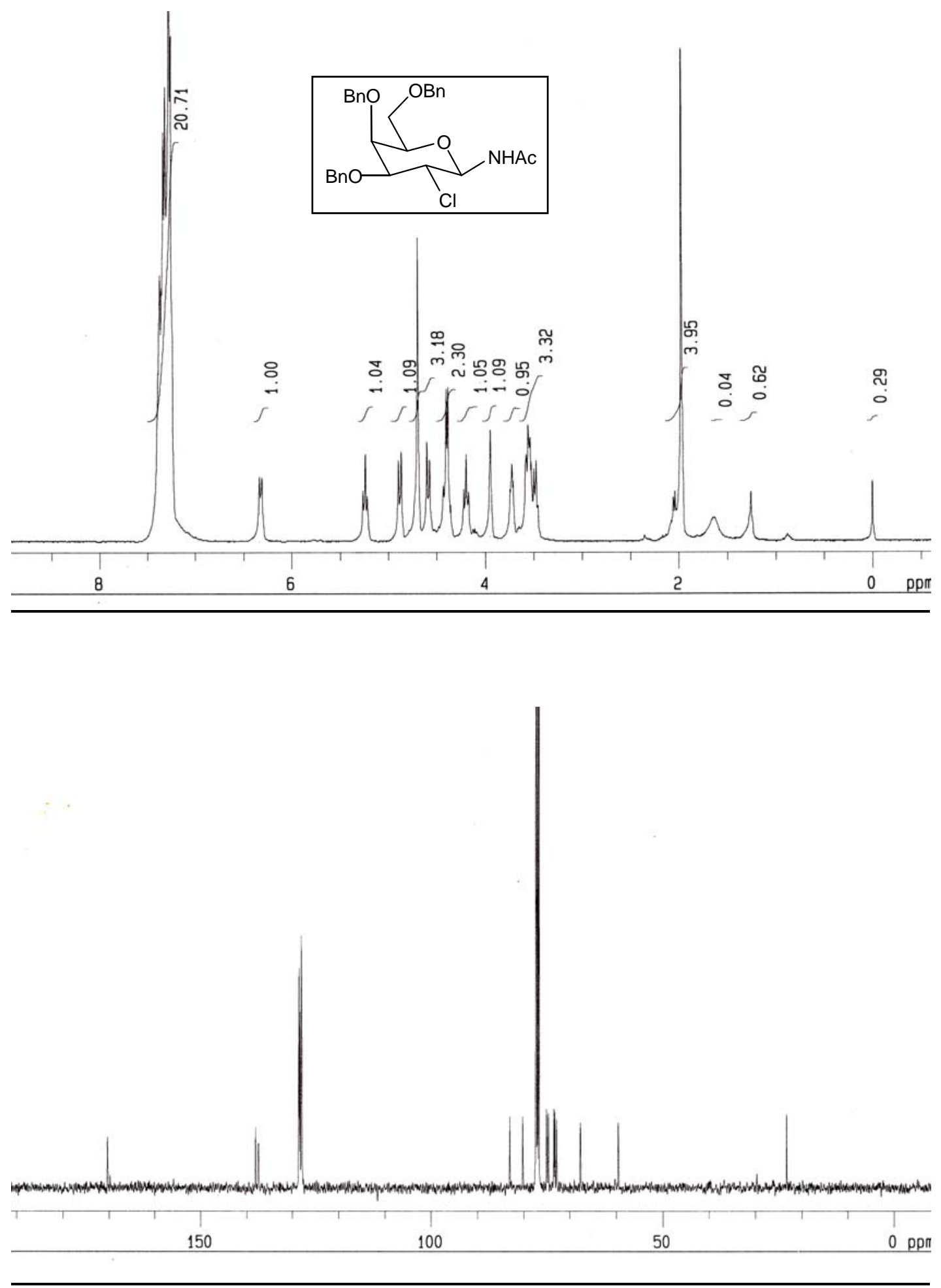
COSY spectra of compound 19.

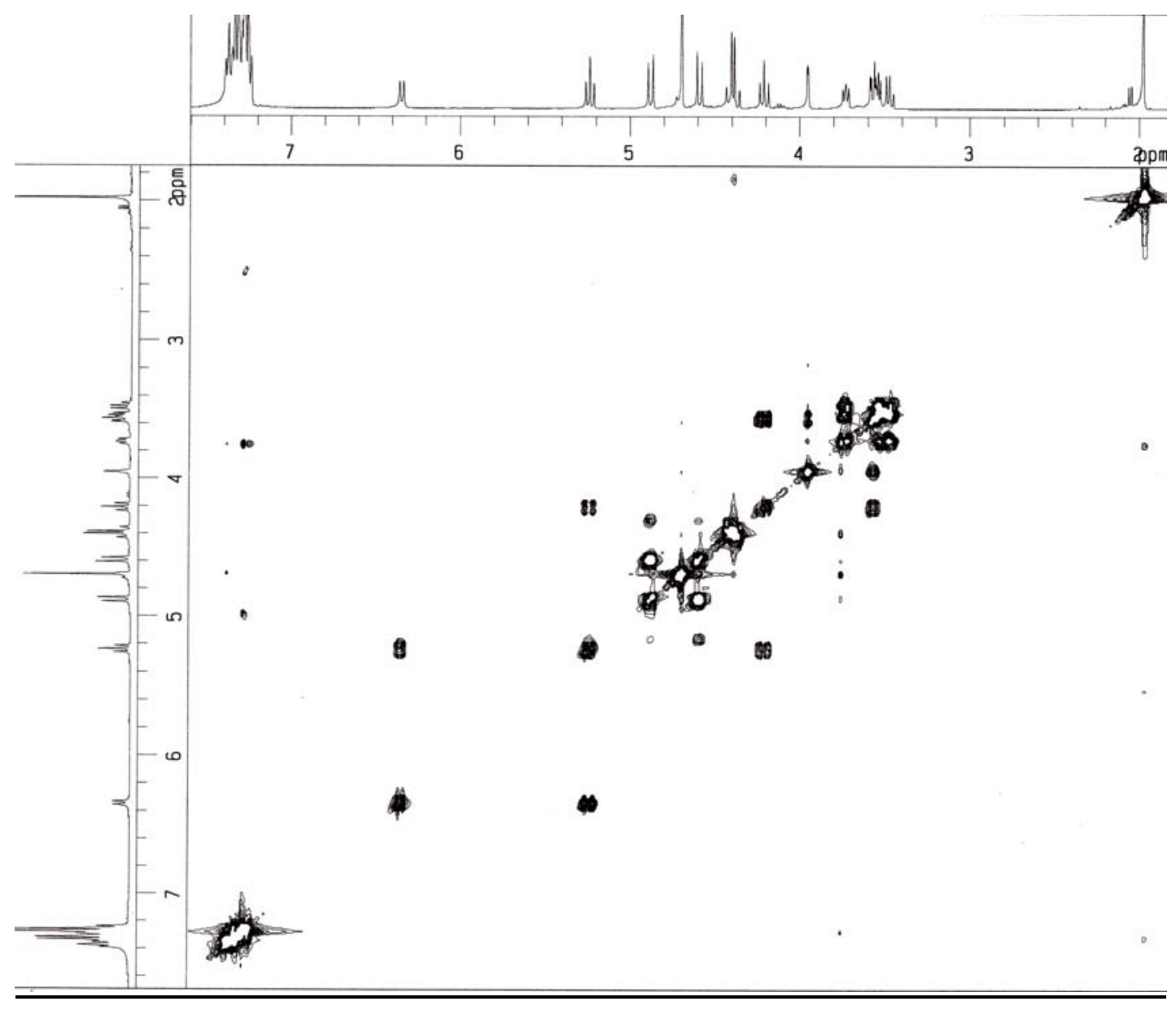




\section{Copy of 1H and 13C spectra for compound 21.}
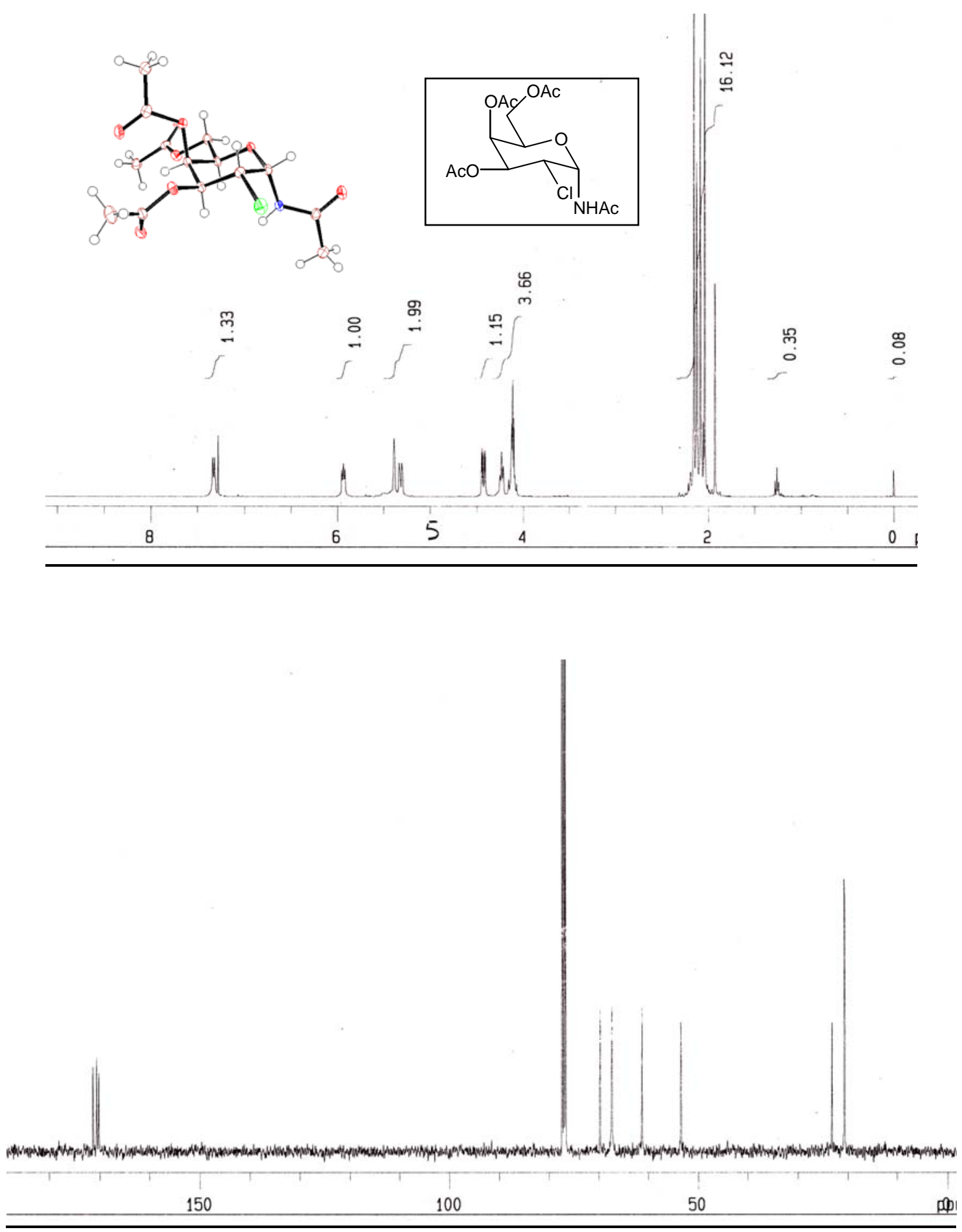
S23

COSY spectra of compound 21.

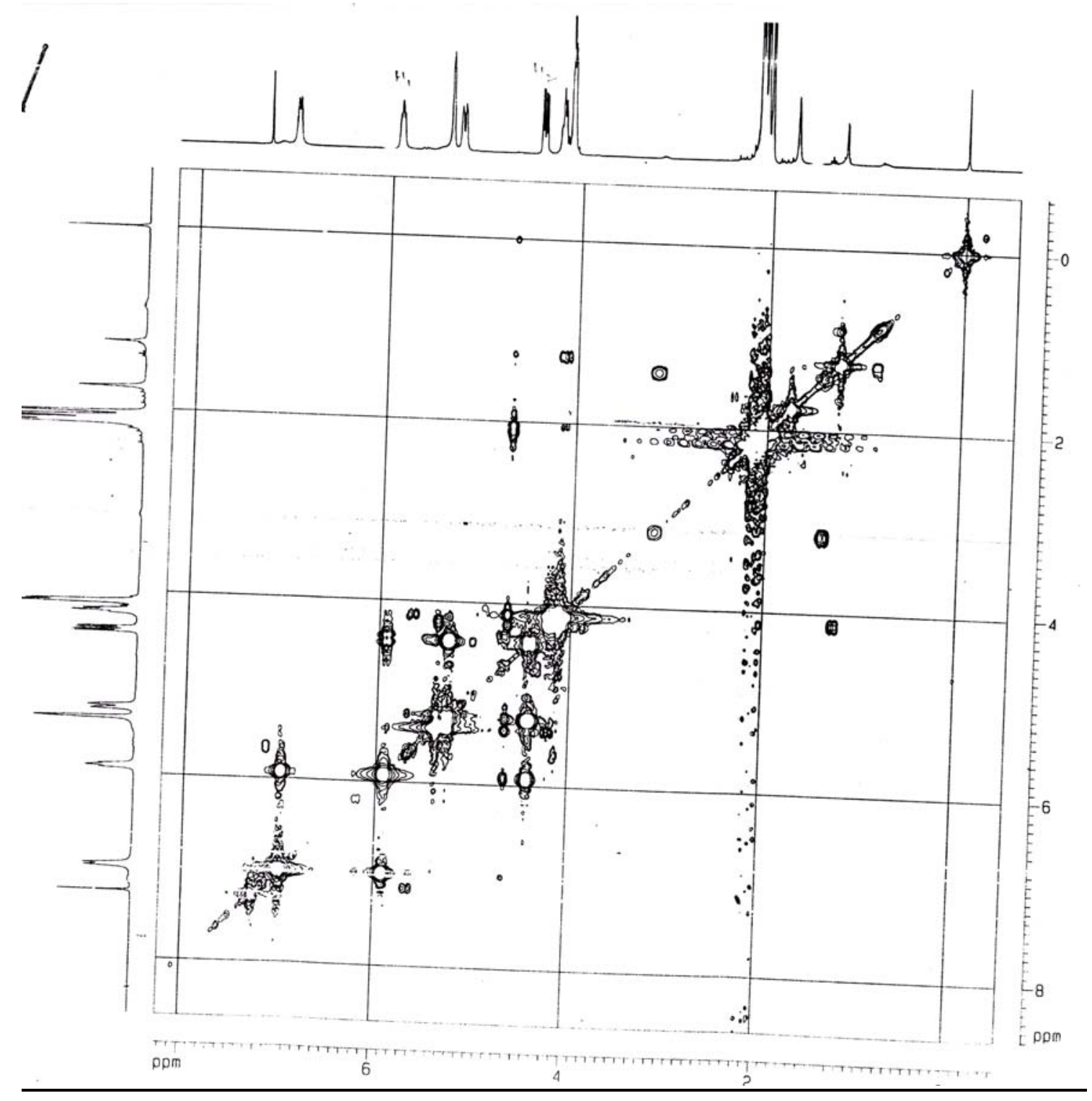




\section{Copy of 1H and 13C spectra for compound 22.}
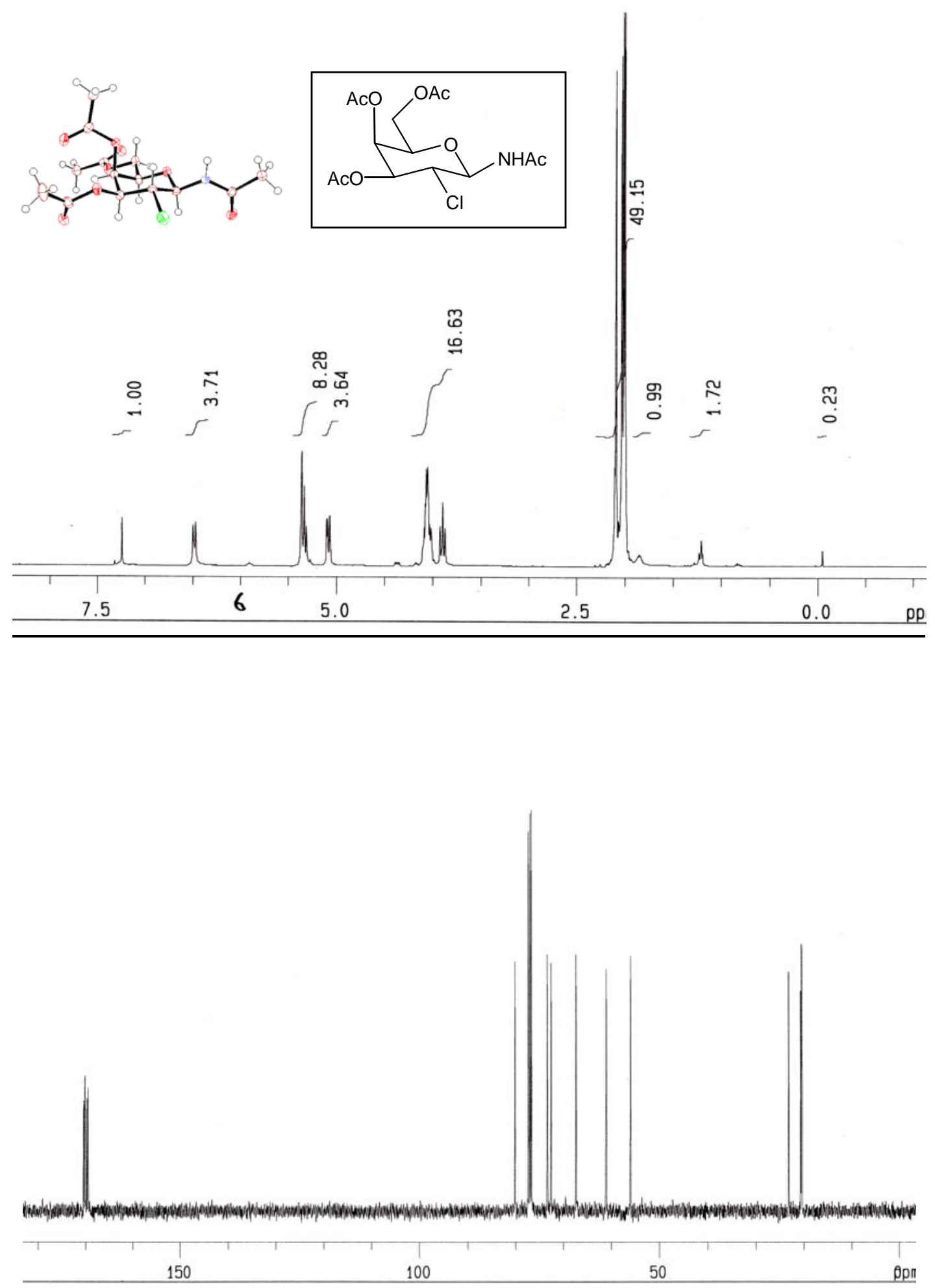
Copy of 1H and 13C spectra for compound 24a.
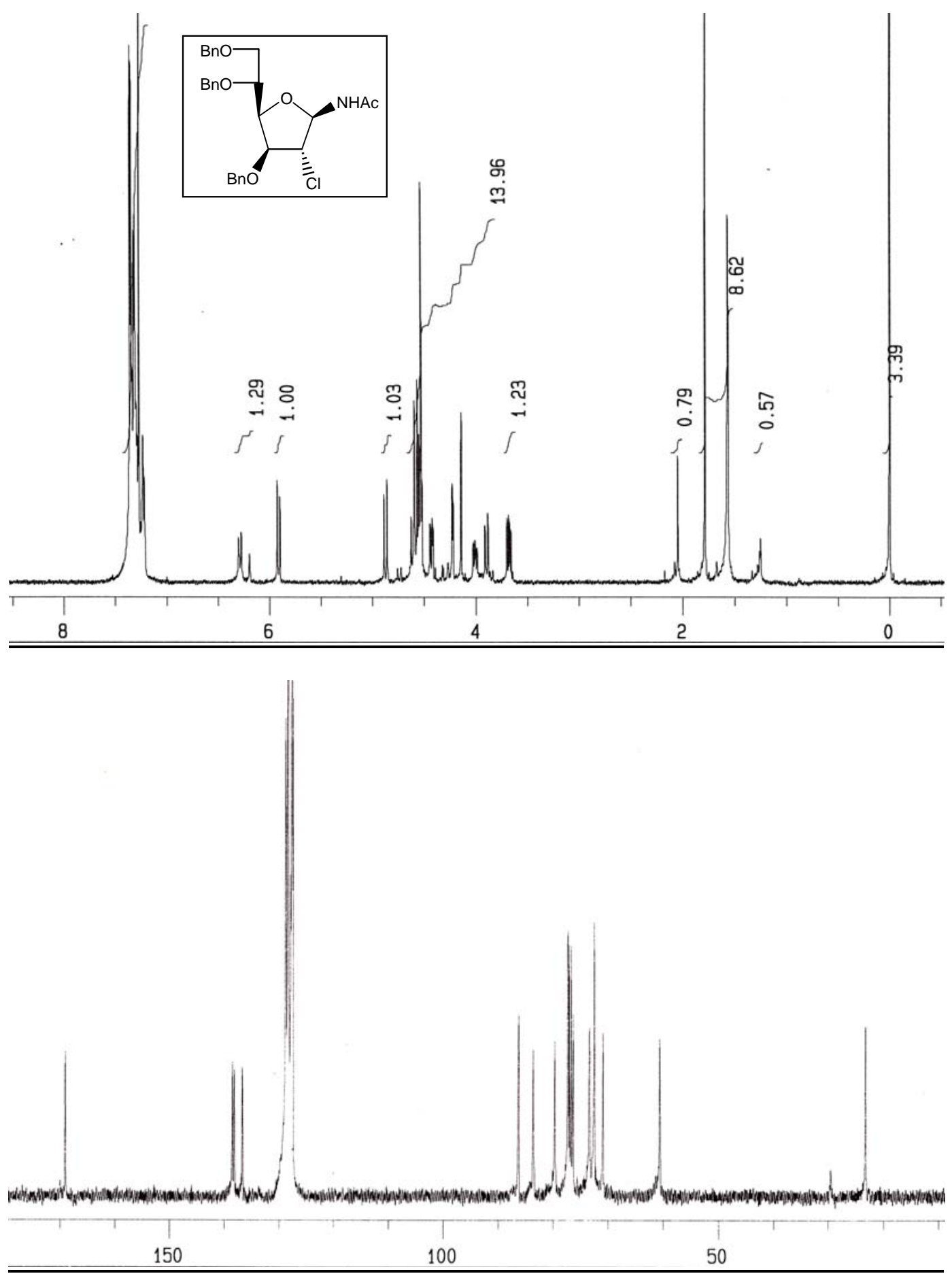
COSY spectra of compound 24a.
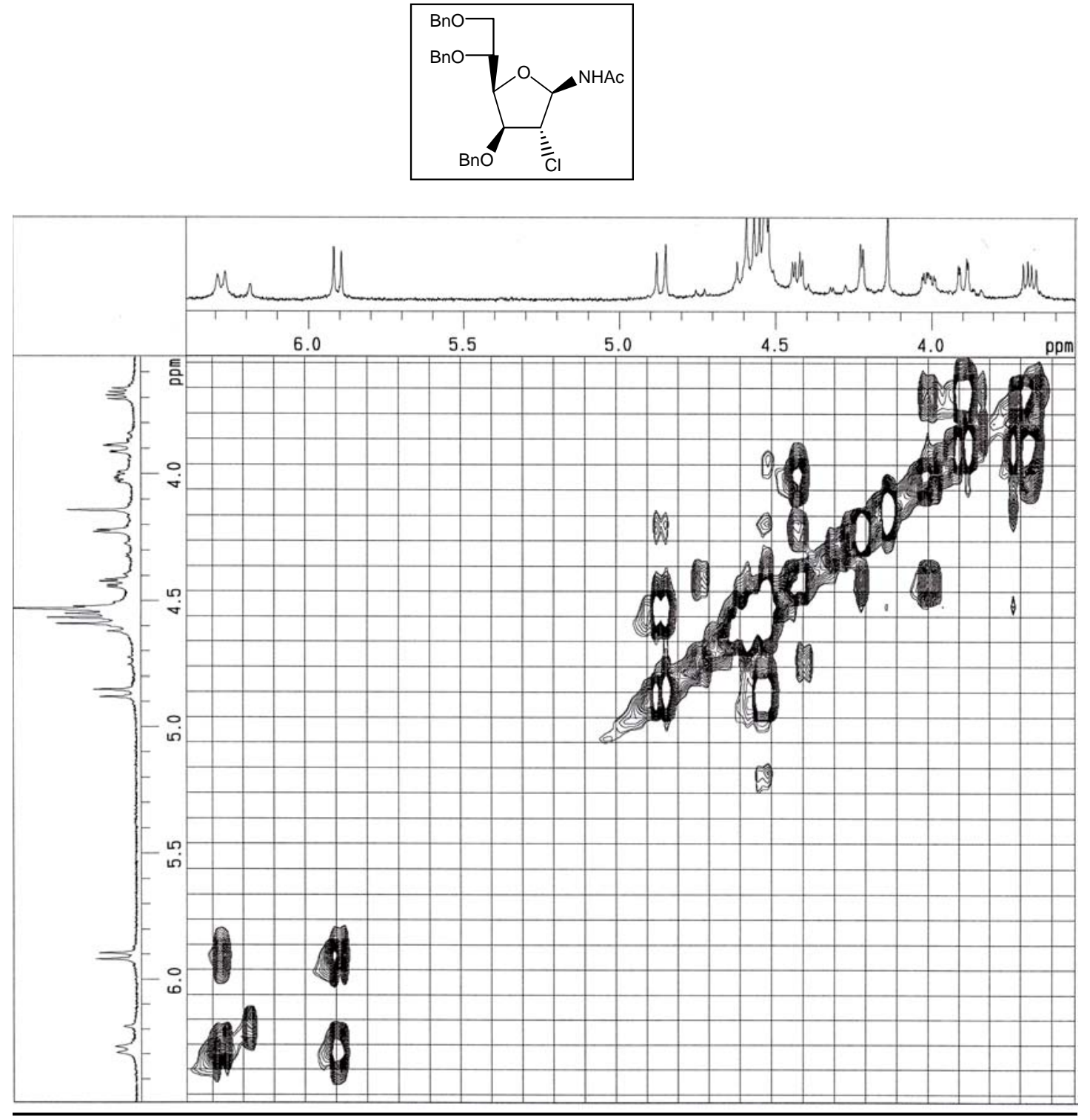
Copy of $1 \mathrm{H}$ and $13 \mathrm{C}$ spectra for compound $24 \mathrm{~b}$.
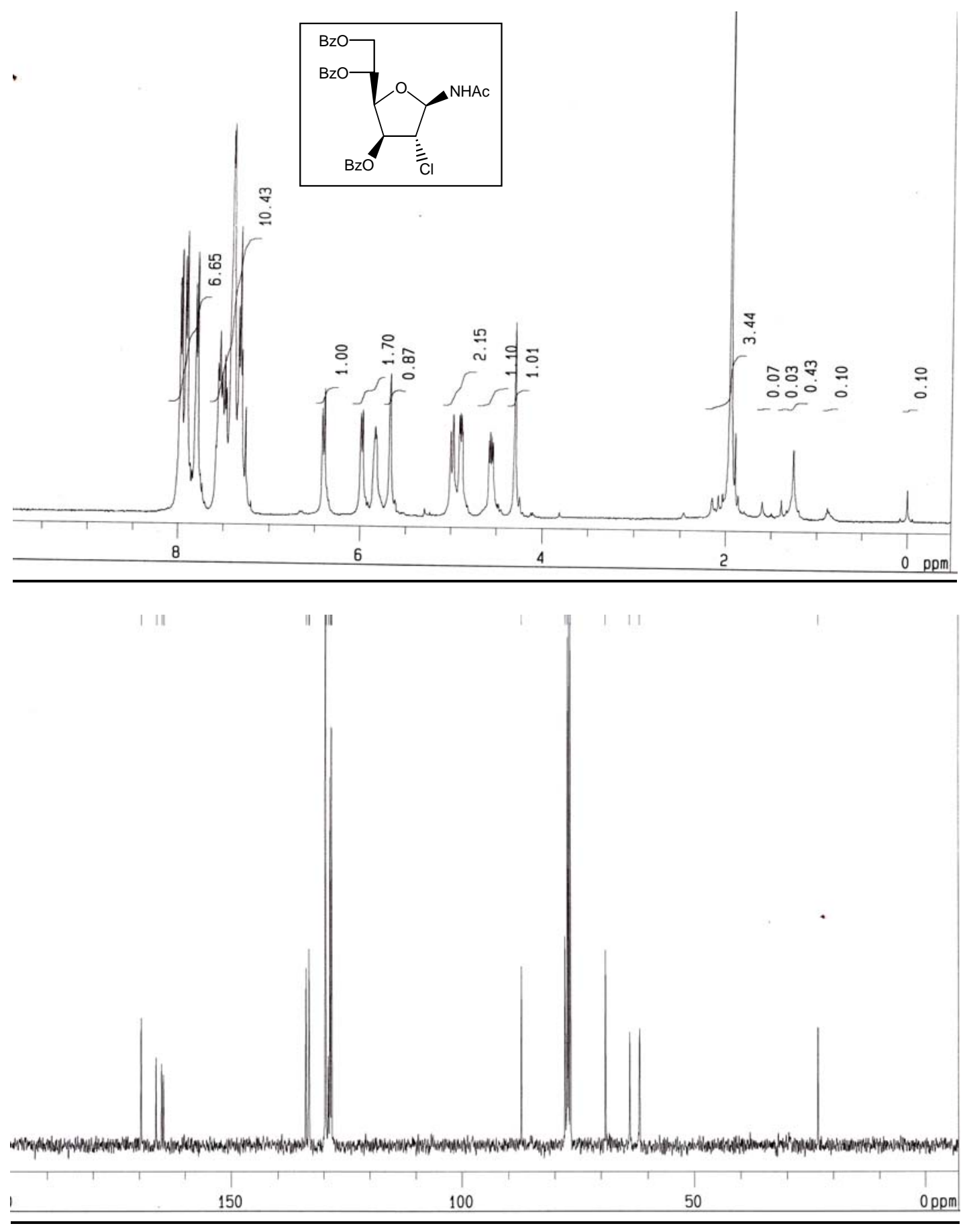
COSY spectrum of compound 24b.
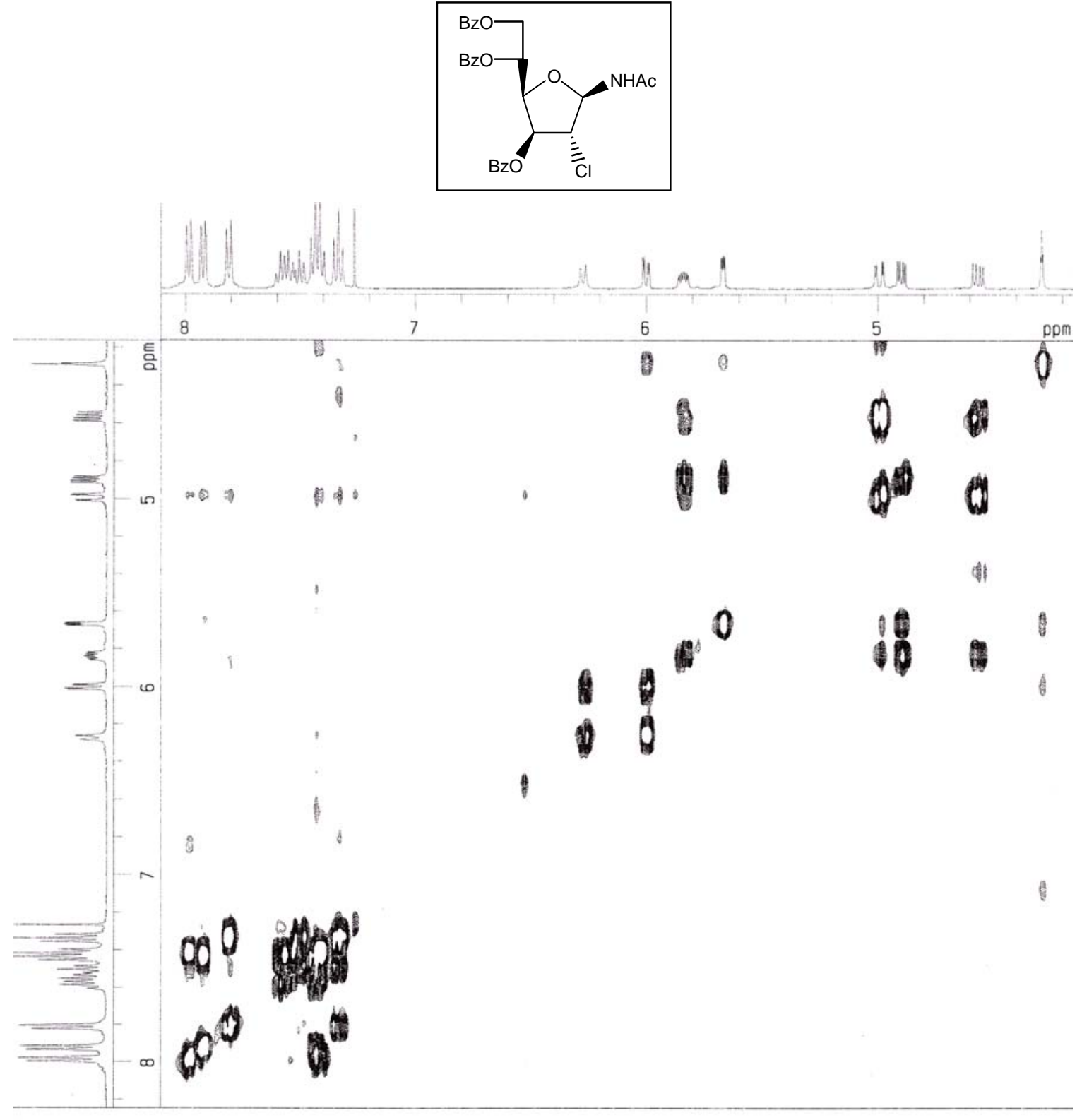
Copy of $1 \mathrm{H}$ and $13 \mathrm{C}$ spectra for compound 24c.
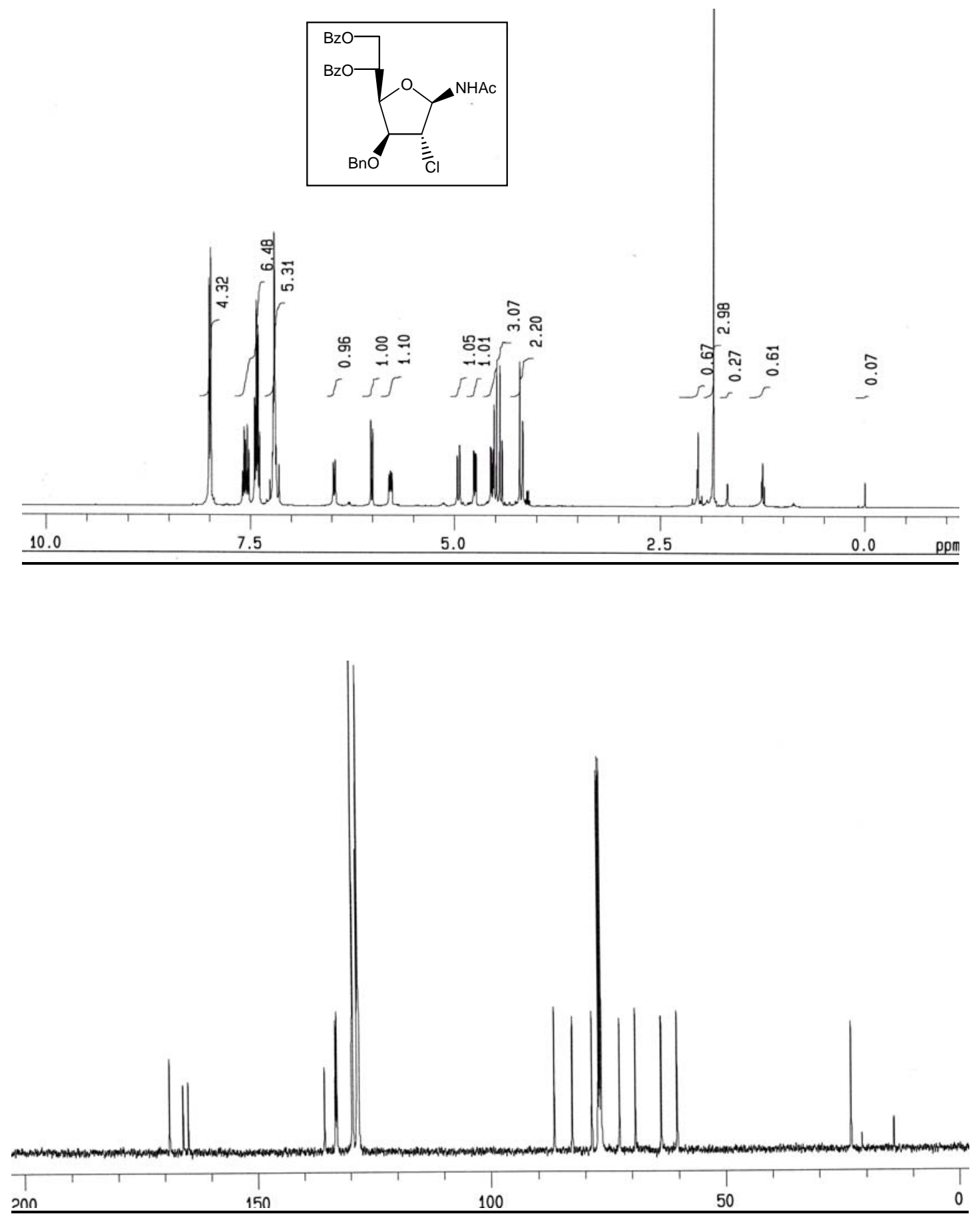
S30

COSY spectra of compound 24c.
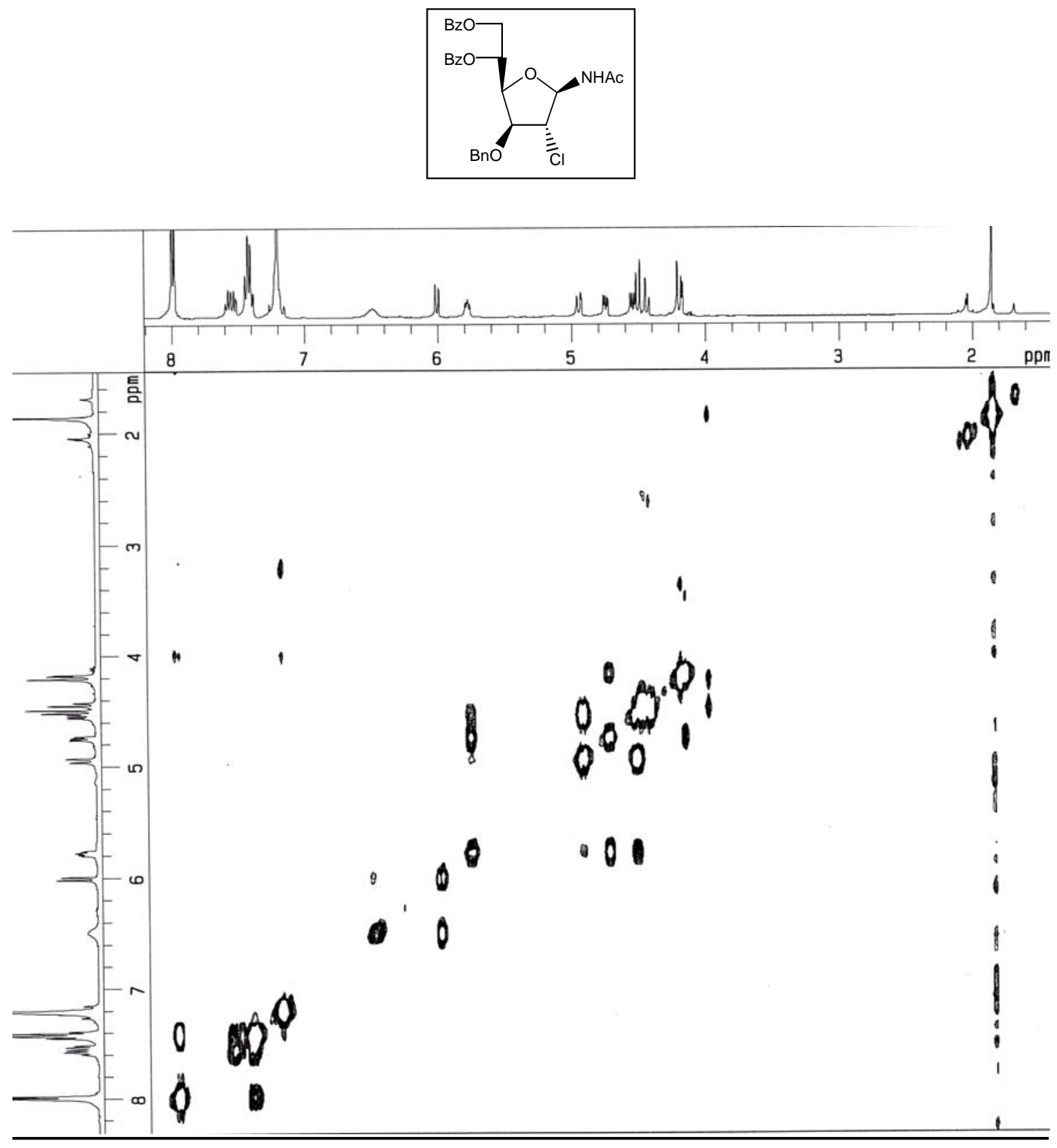
Copy of 1H and 13C spectra for compound 25.
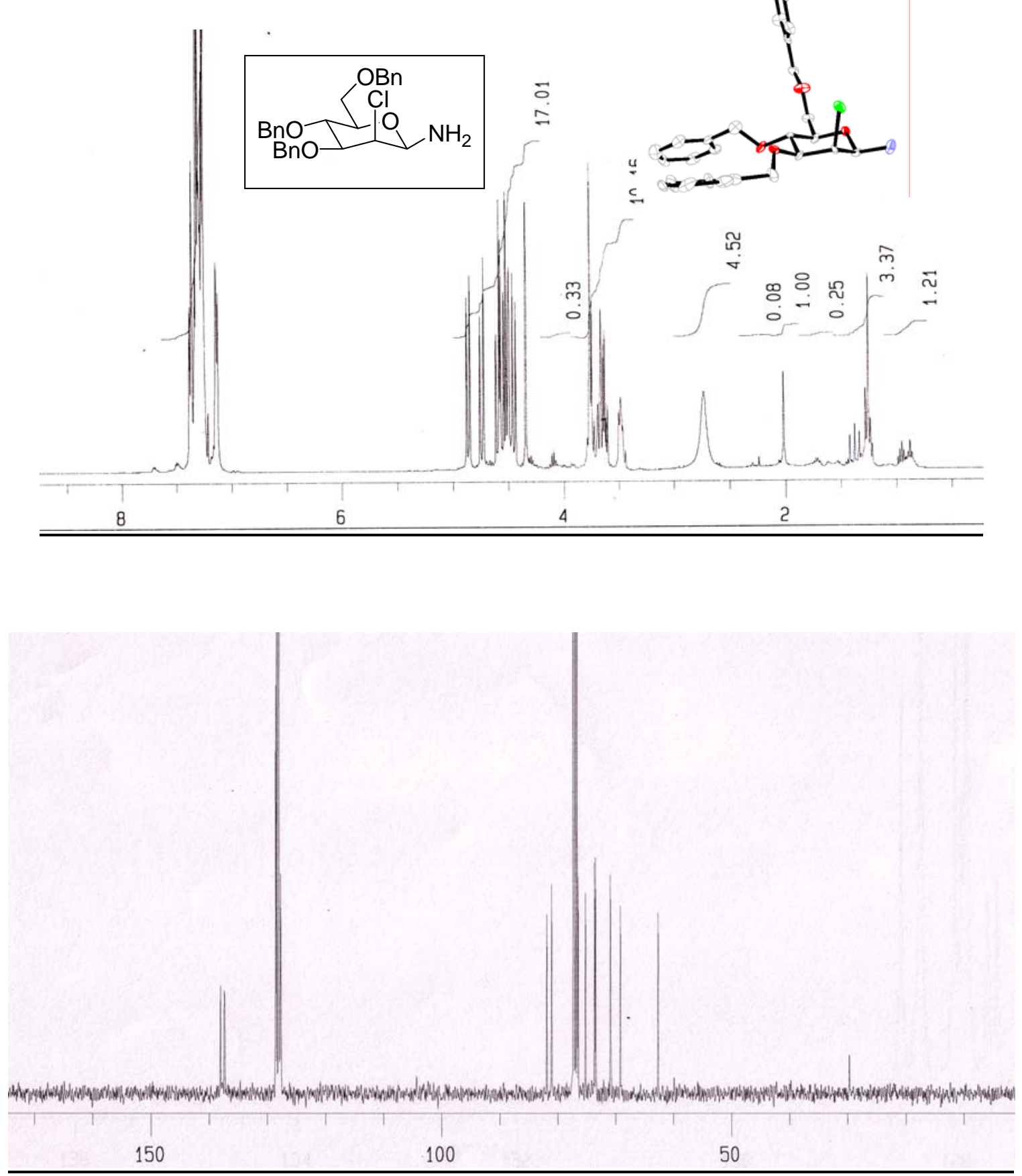


\section{Copy of 1H and 13C spectra for compound 26.}
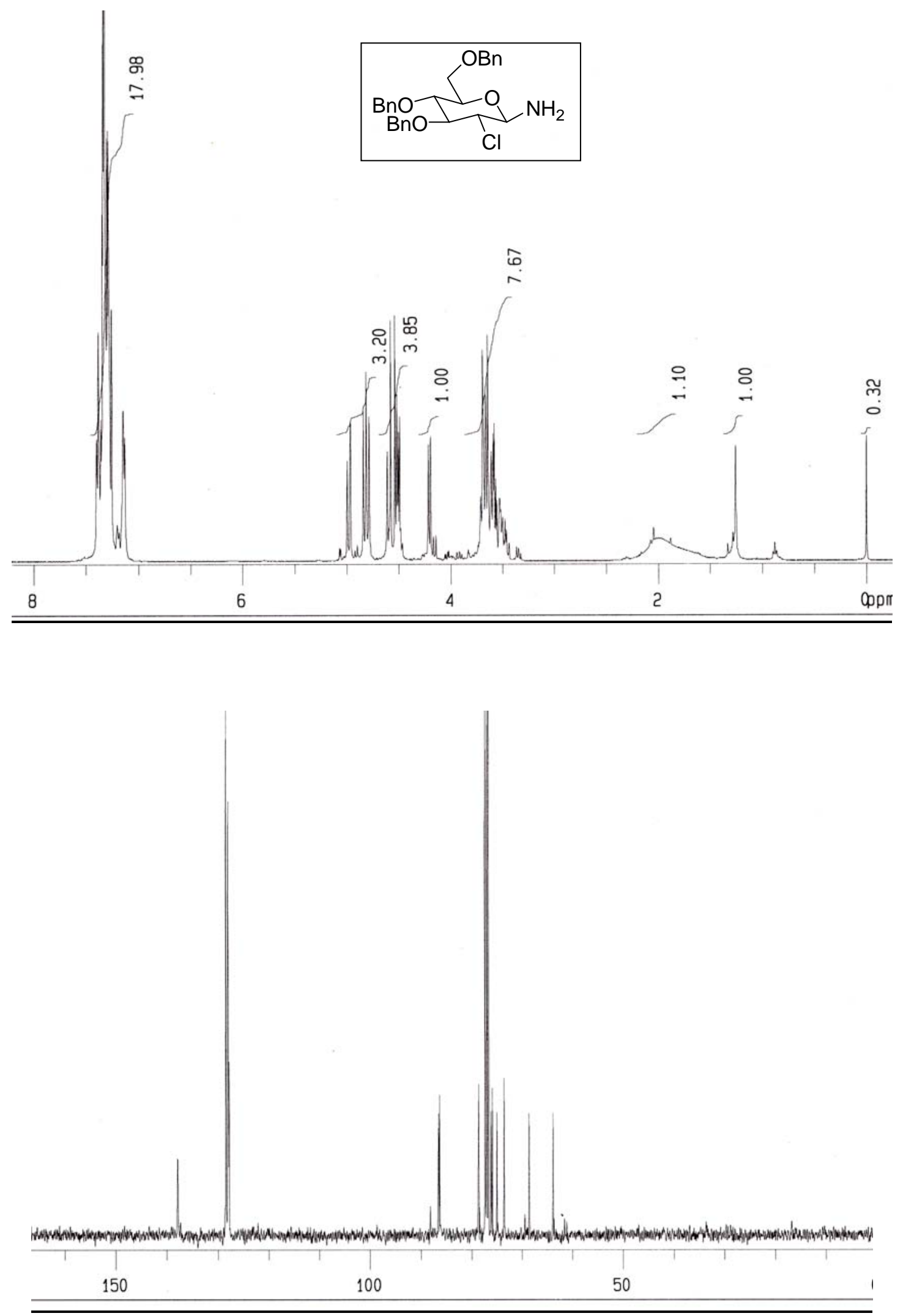
COSY spectra of compound 26.
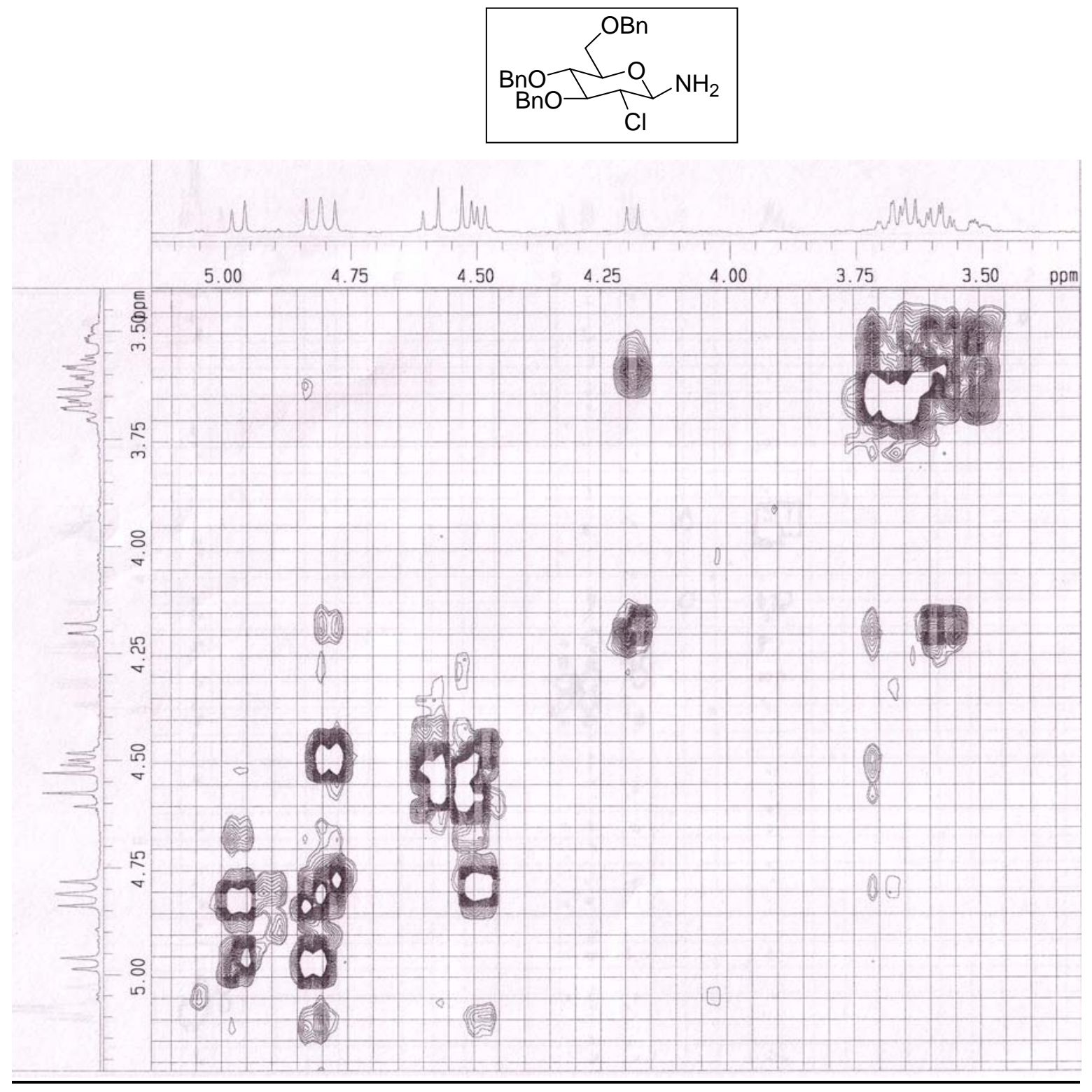
S34

nOe spectra of compound 26.

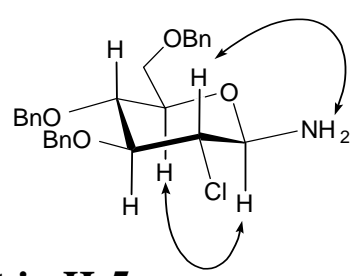

nOe Irradiation of $\mathrm{H}-1$ showing enhancement in $\mathrm{H}-5$

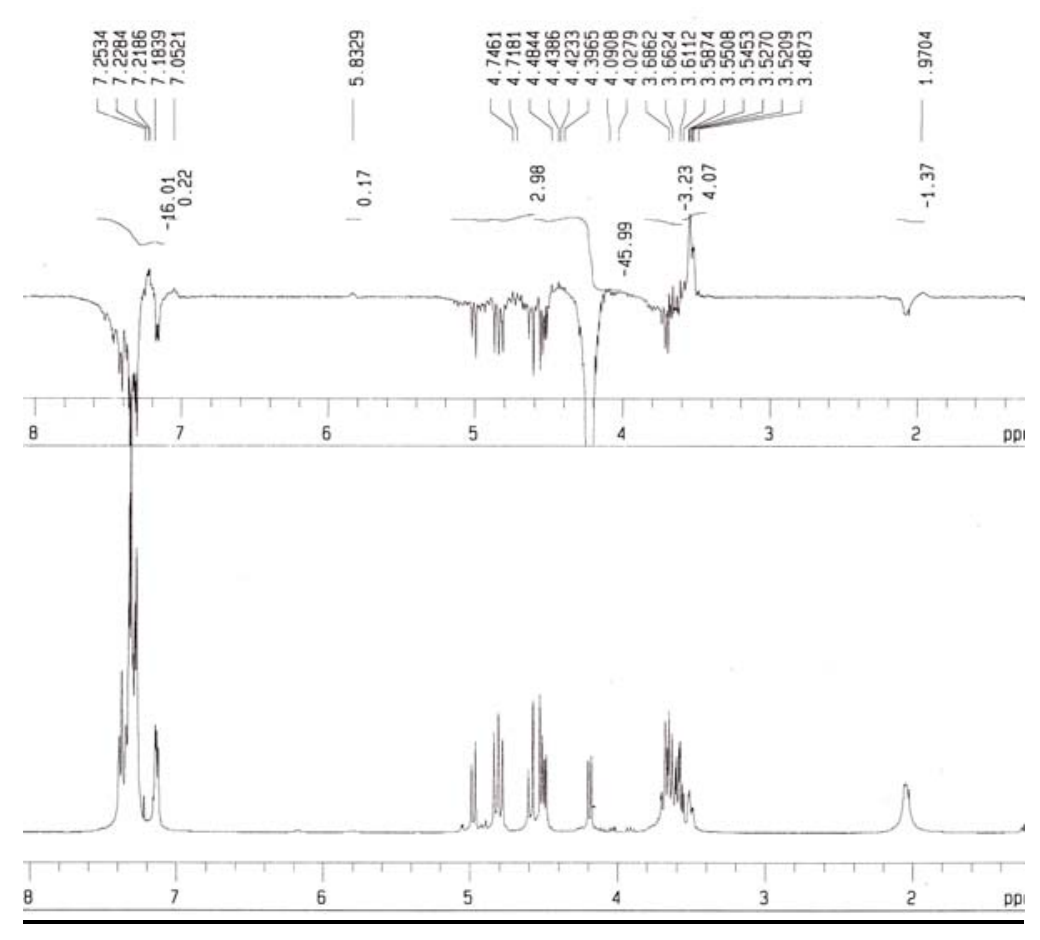

$\underline{\text { nOe Irradiation of } \mathrm{NH}_{2}} \underline{\text { showing enhancement in } \mathrm{H}-2}$

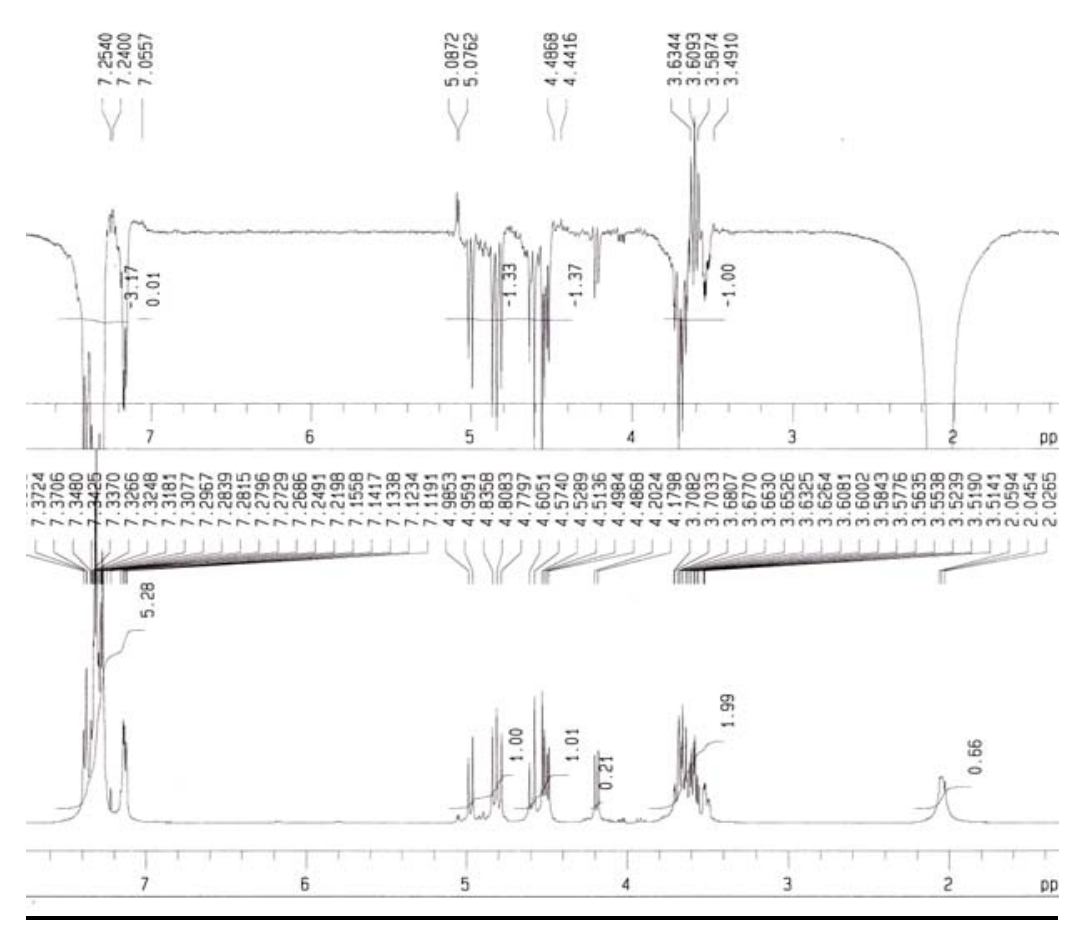




\section{Copy of 1H and 13C spectra for compound 27.}
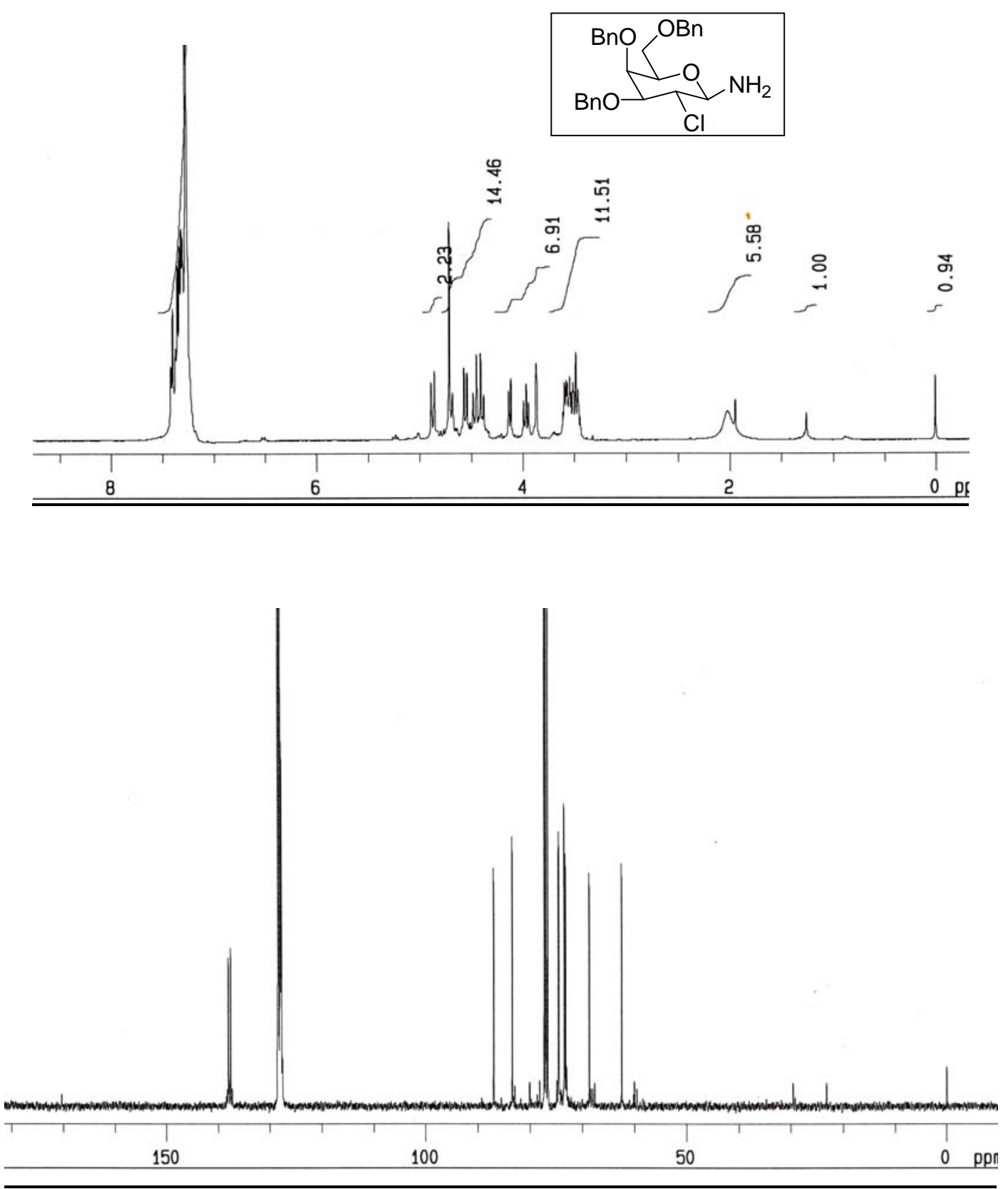
S36

COSY spectra of compound 27.
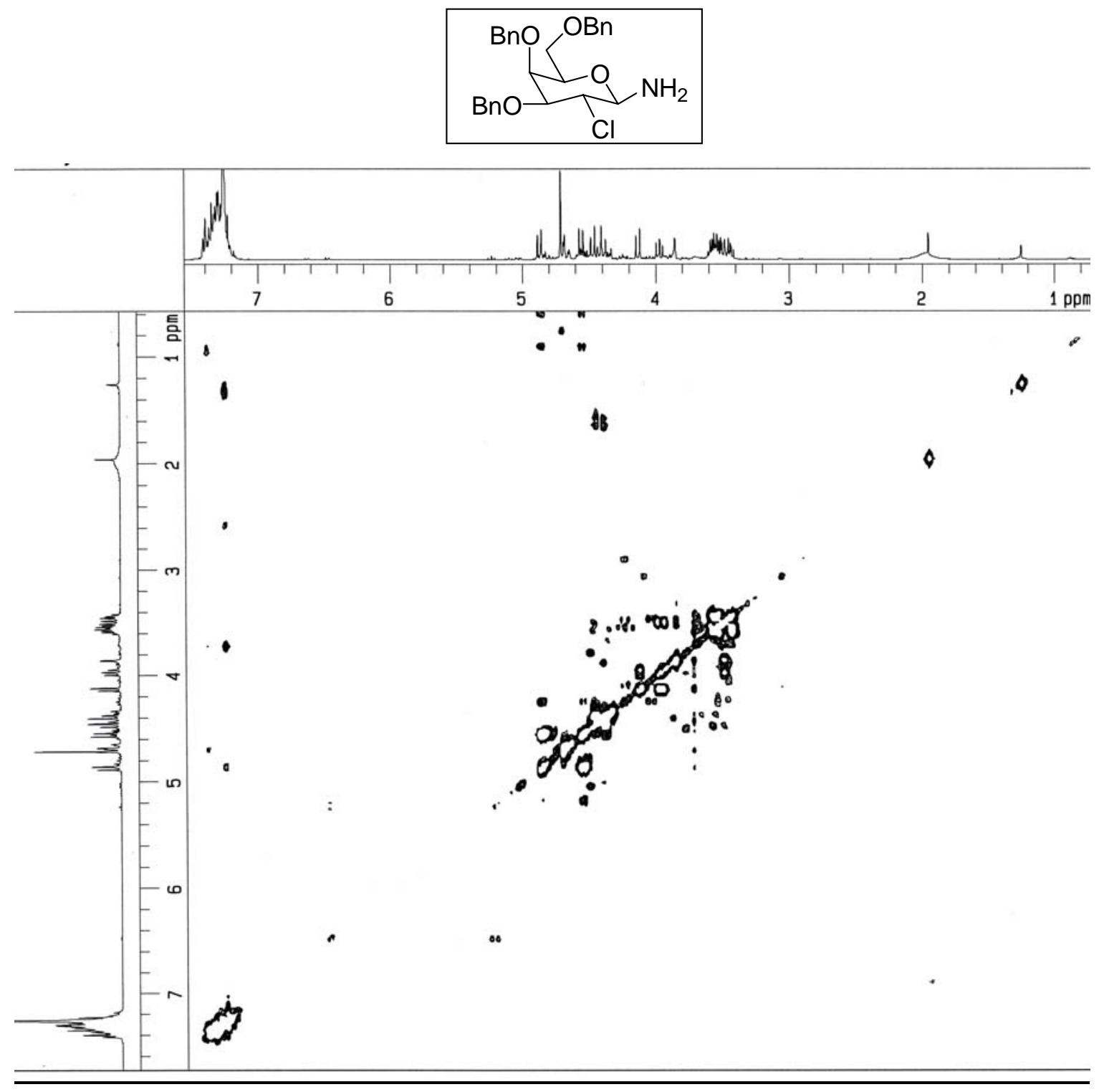
nOe spectra of compound 27.

nOe Irradiation of $\mathrm{H}-1$ showing enhancement in $\mathrm{H}-3$ and $\mathrm{H}-5$
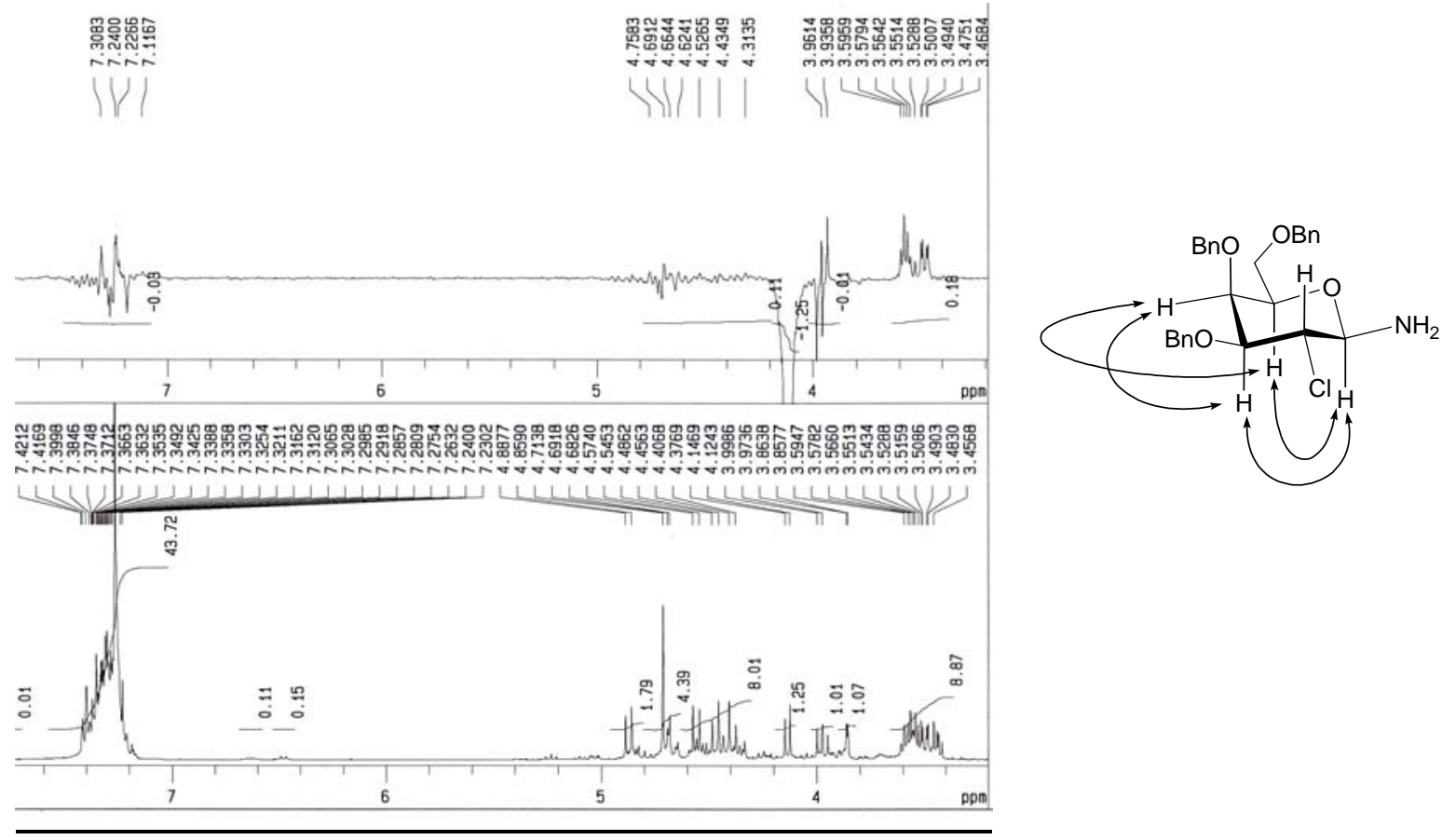

$\underline{\text { nOe Irradiation of } \mathrm{H}-4 \text { showing enhancement in } \mathrm{H}-3 \text { and } \mathrm{H}-5}$

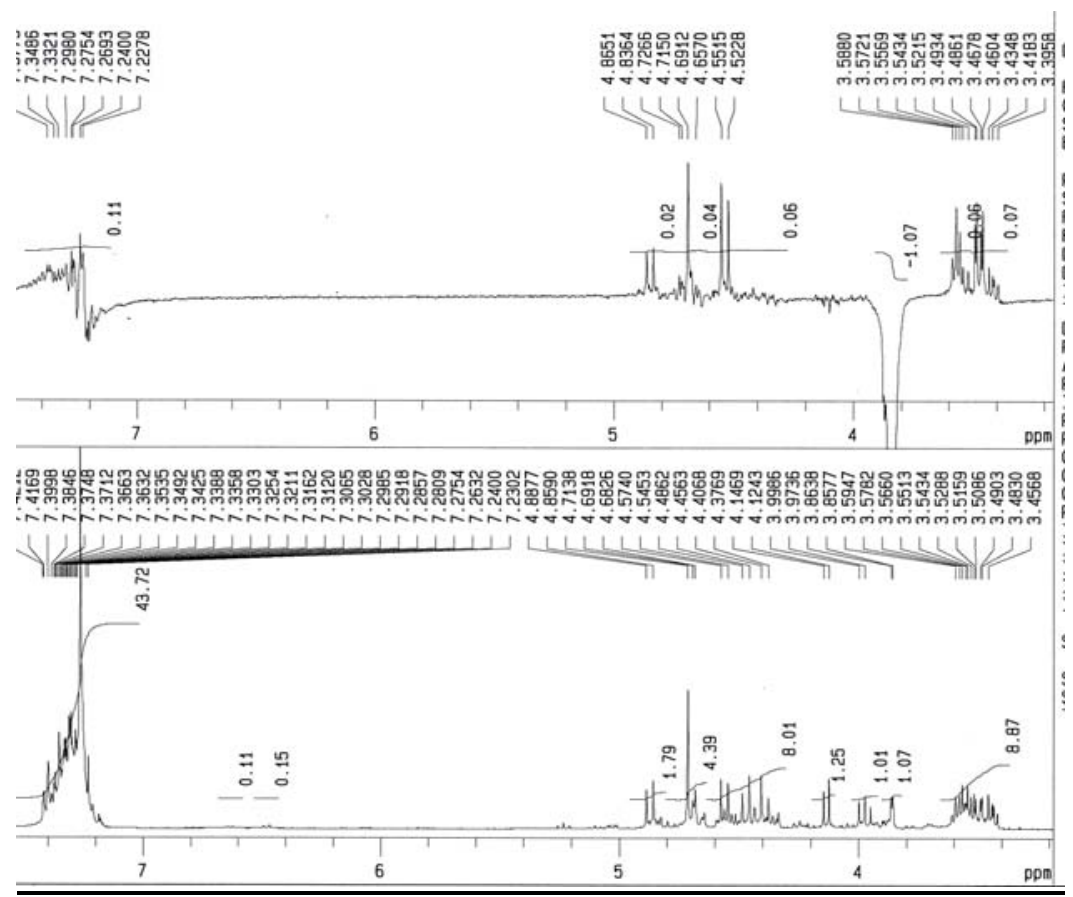


Copy of $1 \mathrm{H}$ and 13C spectra for compound 28.
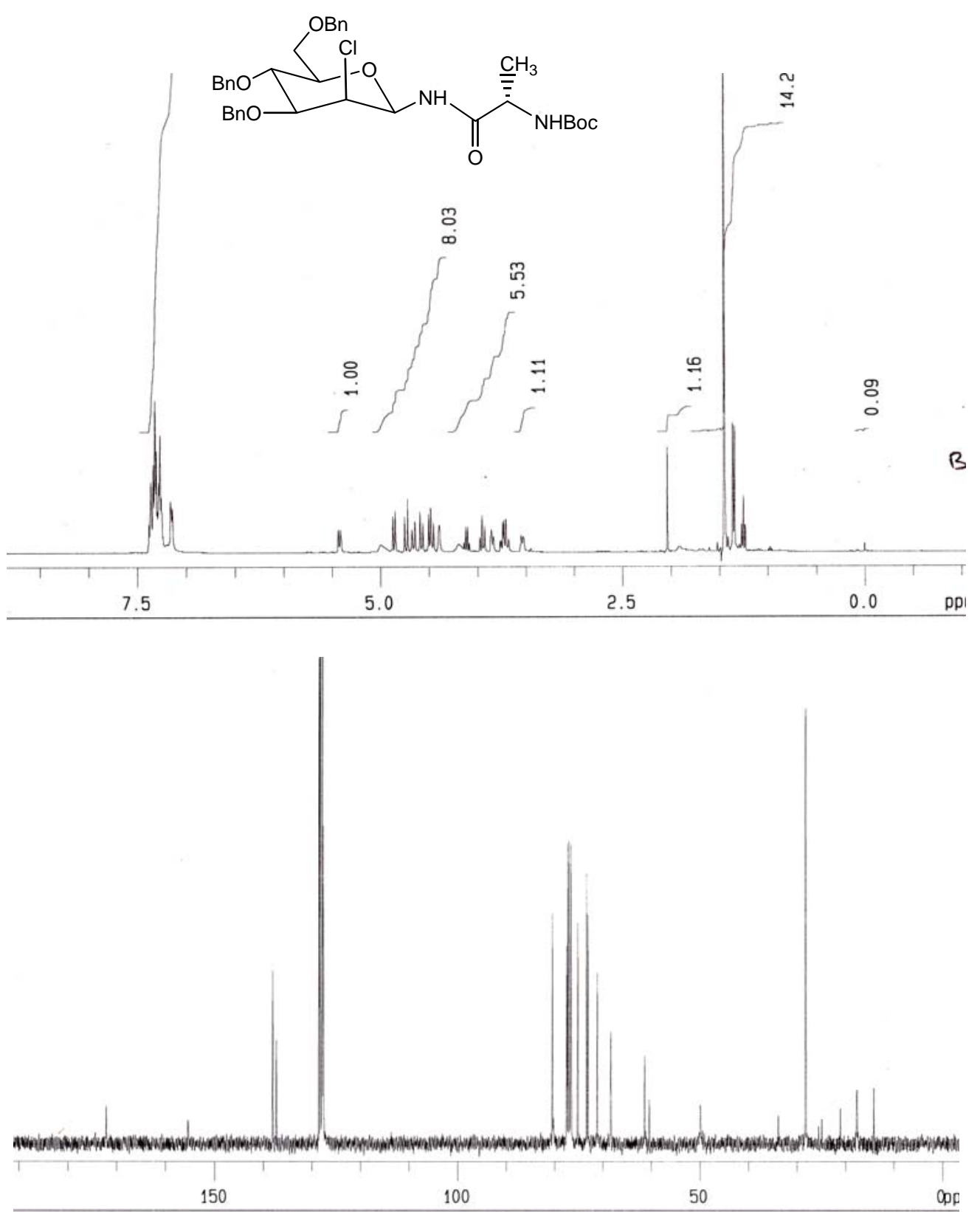
COSY spectra of compound 28.

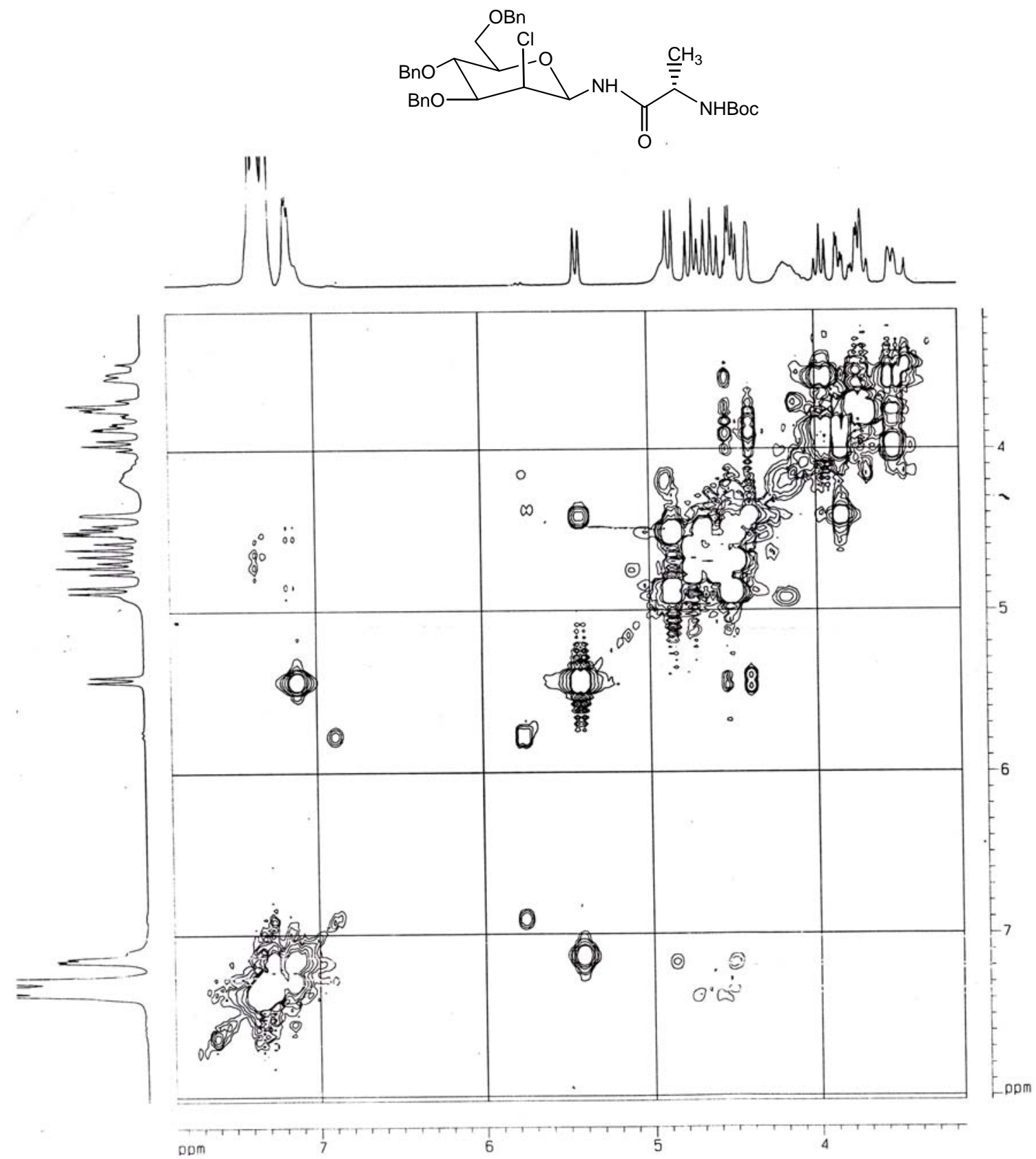


nOe spectra of compound 28.

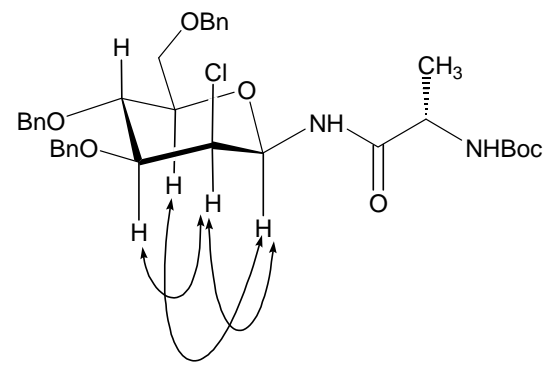

nOe Irradiation of $\mathrm{H}-2$ showing enhancement in $\mathrm{H}-1$ and $\mathrm{H}-3$

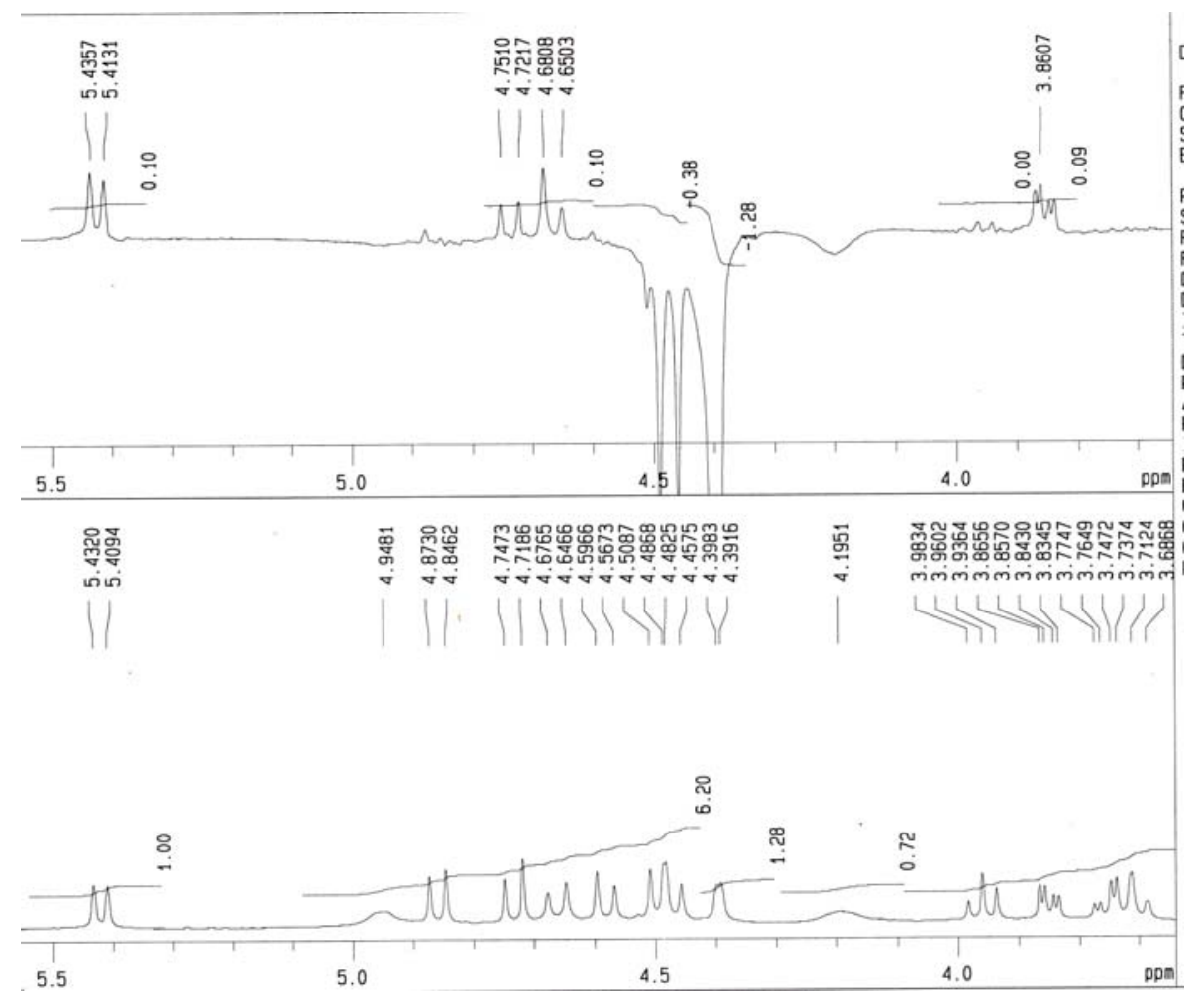


nOe Irradiation of $\mathrm{H}-3$ showing enhancement in $\mathrm{H}-2$ and $\mathrm{H}-1$

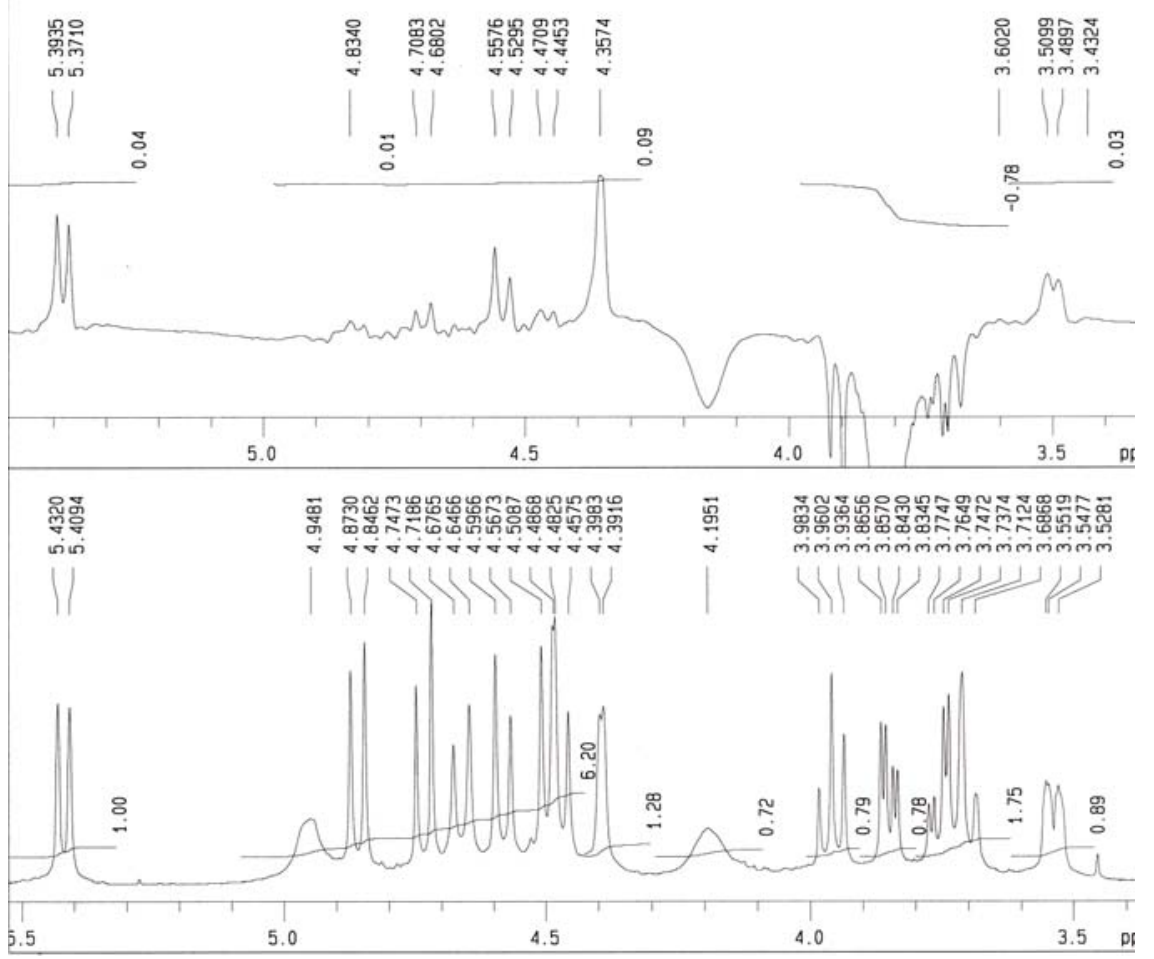

nOe Irradiation of $\mathrm{H}-5$ showing enhancement in $\mathrm{H}-1$ and $\mathrm{H}-3$

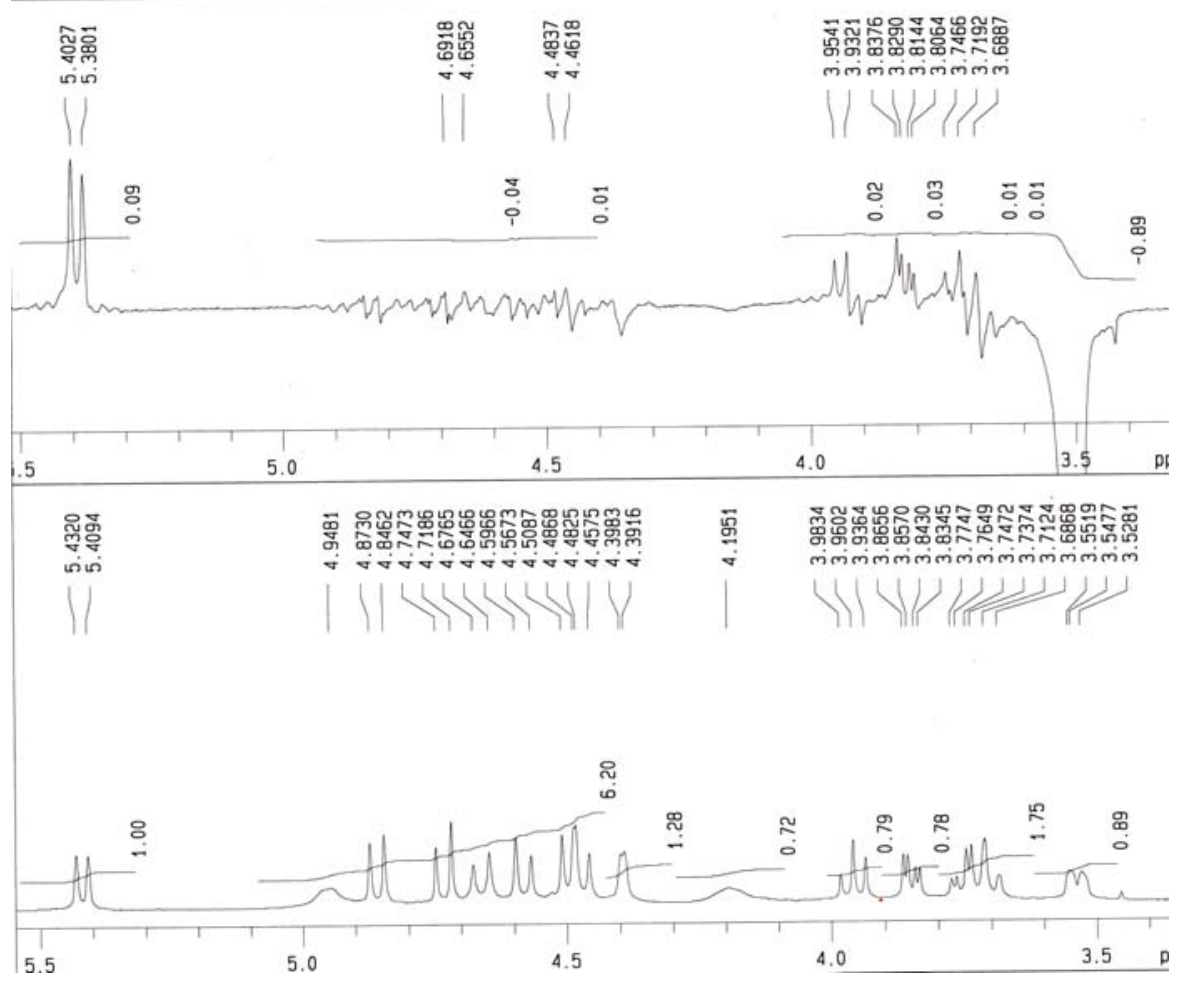


S42

Copy of 1H and 13C spectra for compound 29.
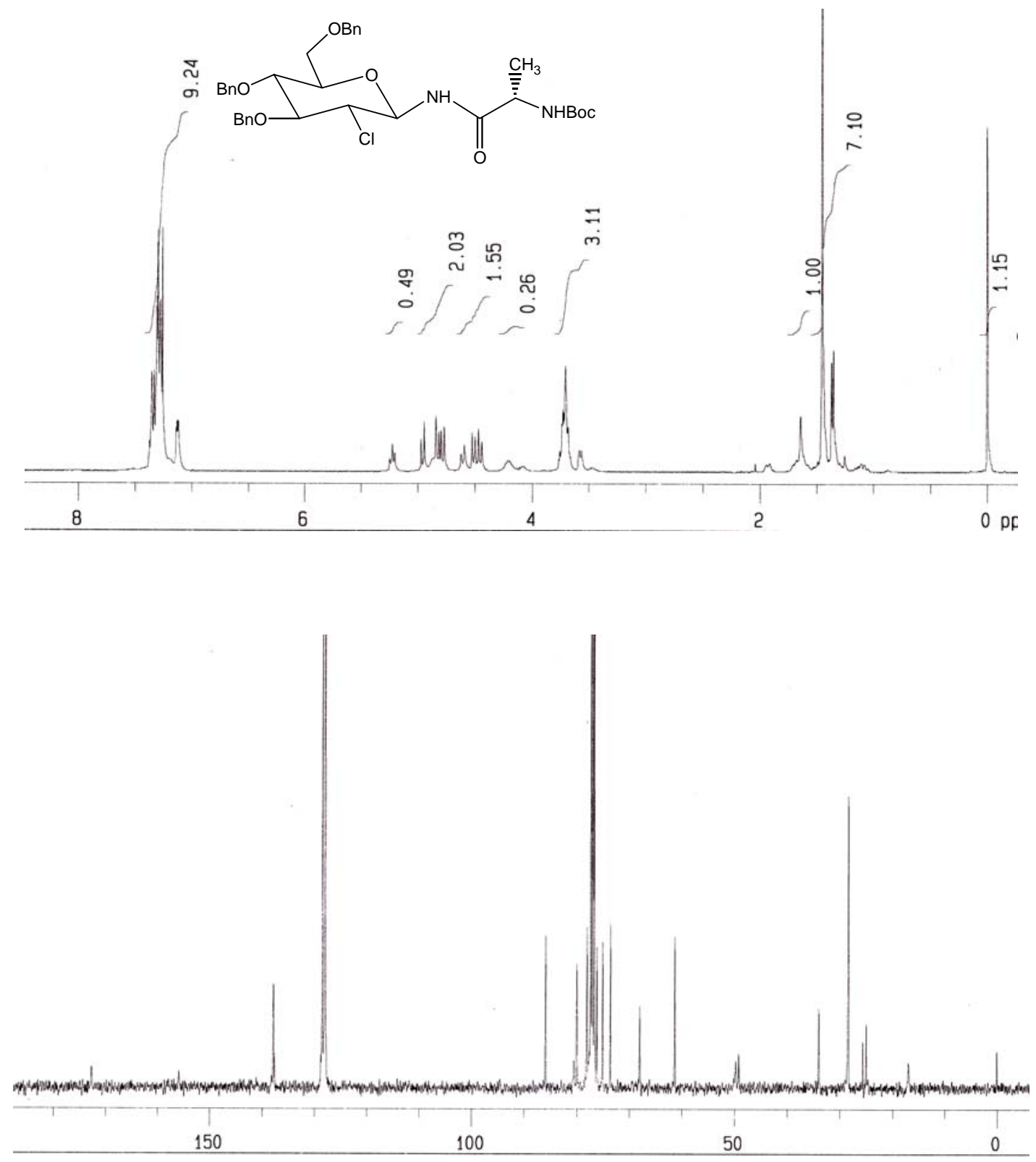


\section{Copy of 1H and 13C spectra for compound 30.}
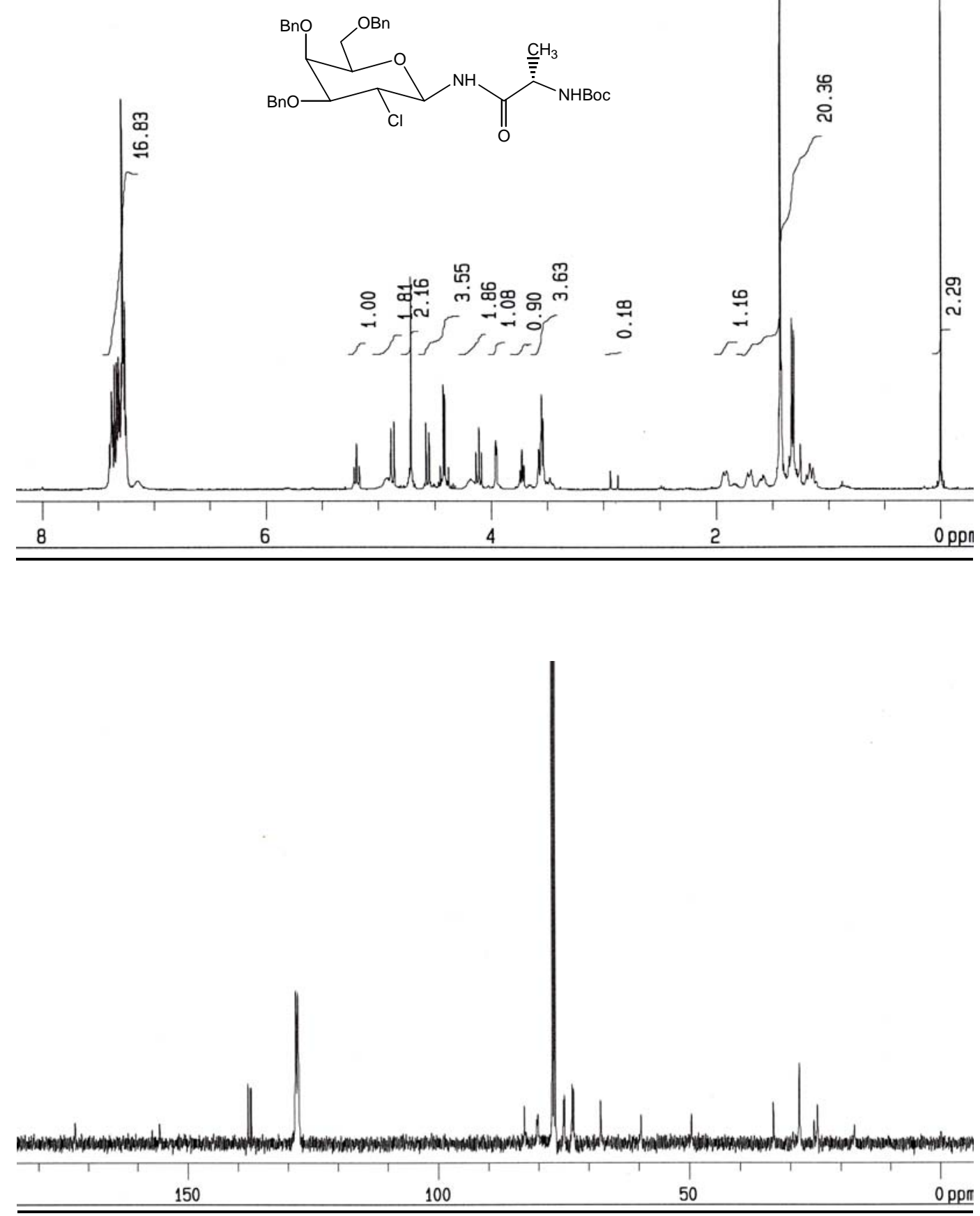


\section{Copy of 1H and 13C spectra for compound 31.}
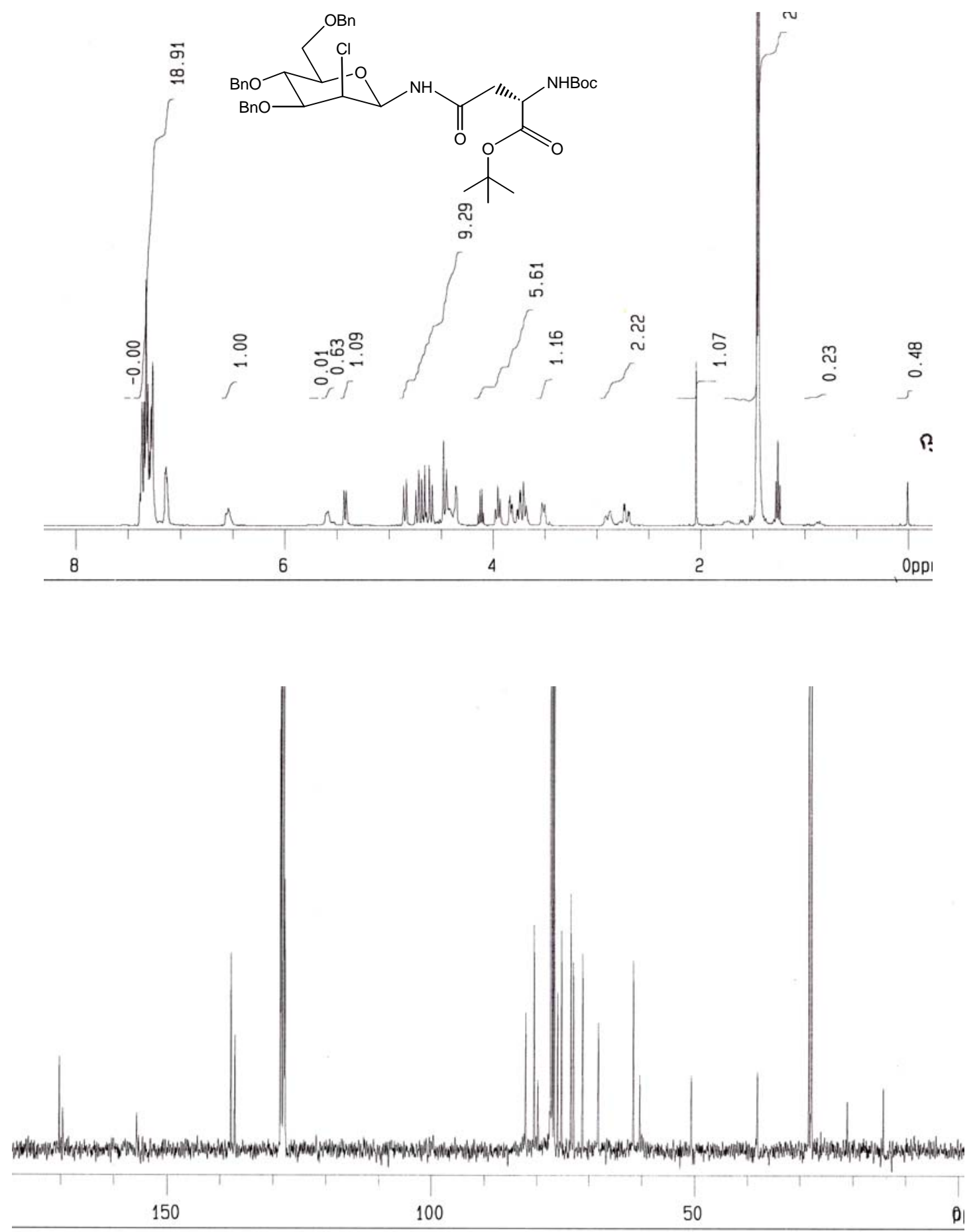


\section{Copy of $1 \mathrm{H}$ and $13 \mathrm{C}$ spectra for compound 32.}
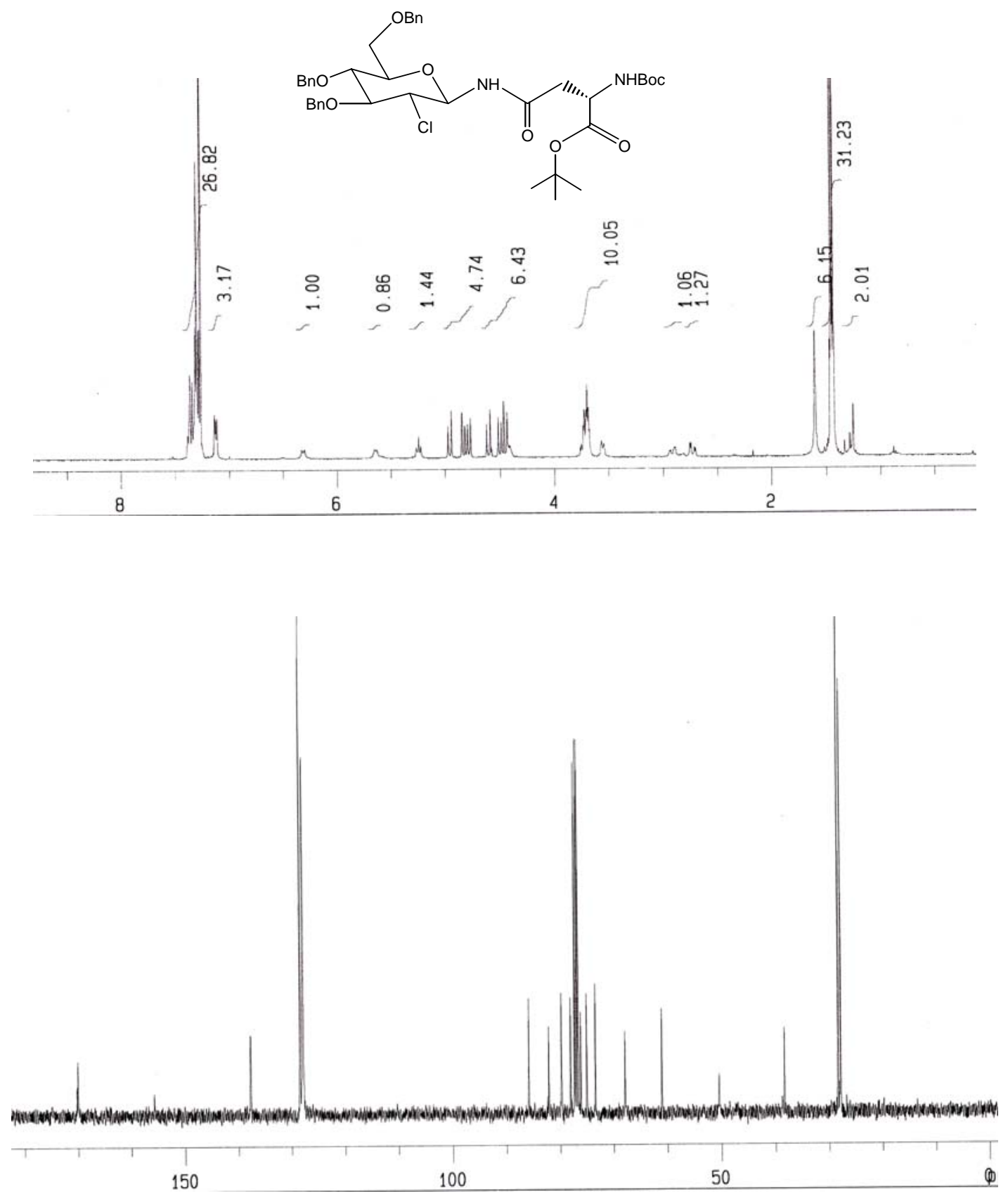
S46

Copy of $1 \mathrm{H}$ and $13 \mathrm{C}$ spectra for compound 33.
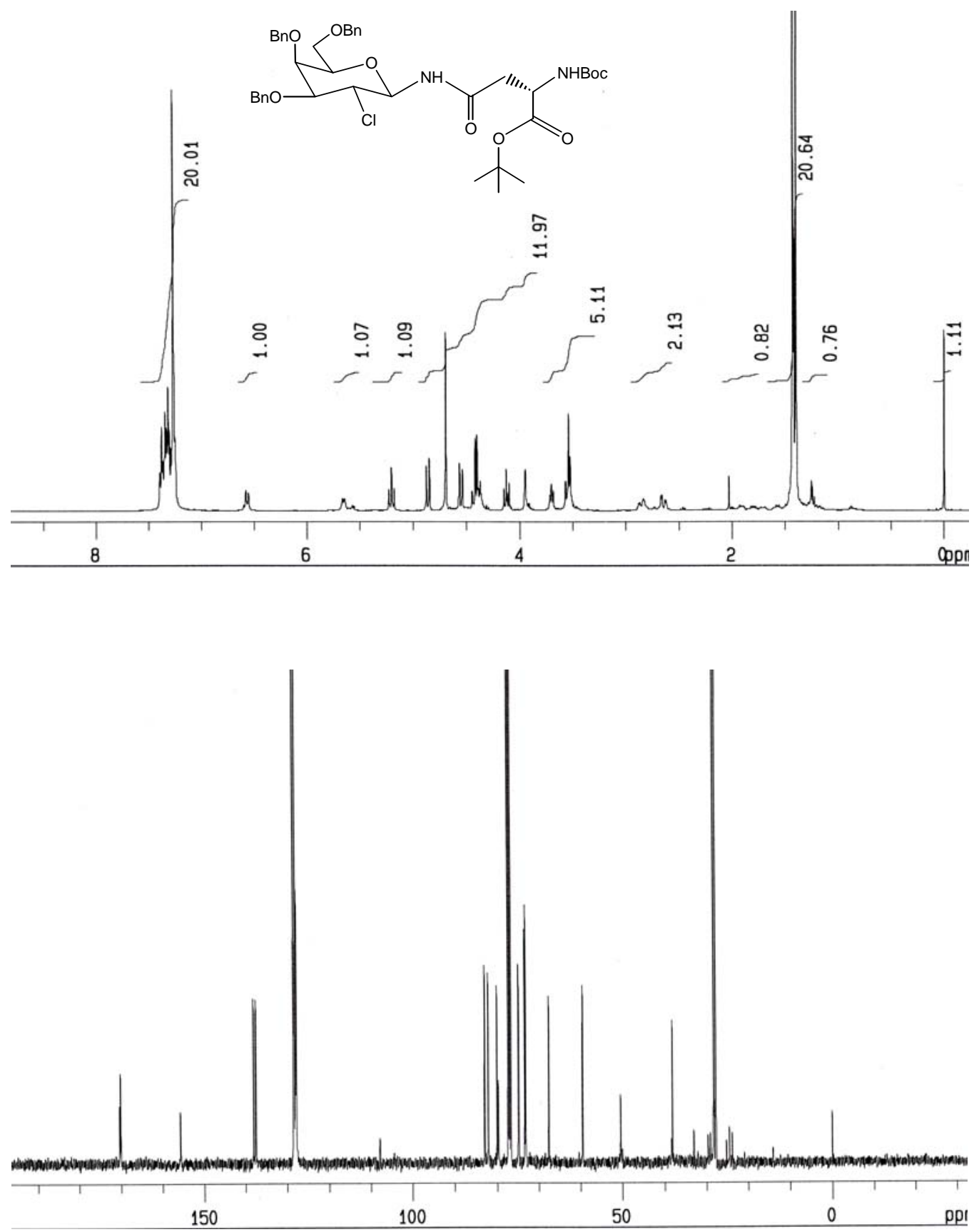


\section{Copy of $1 \mathrm{H}$ and 13C spectra for compound 34.}
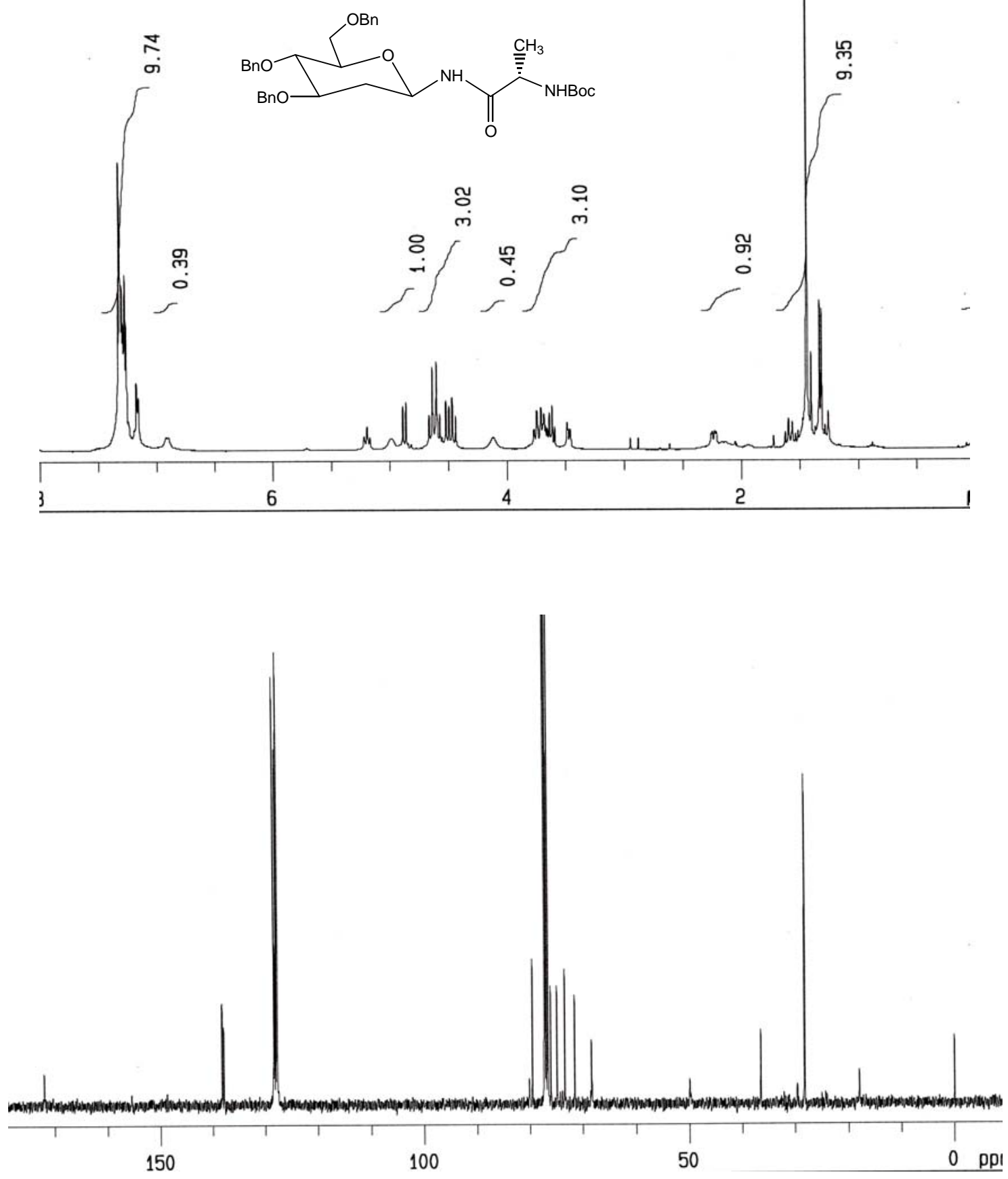


\section{Copy of 1H and 13C spectra for compound 35.}
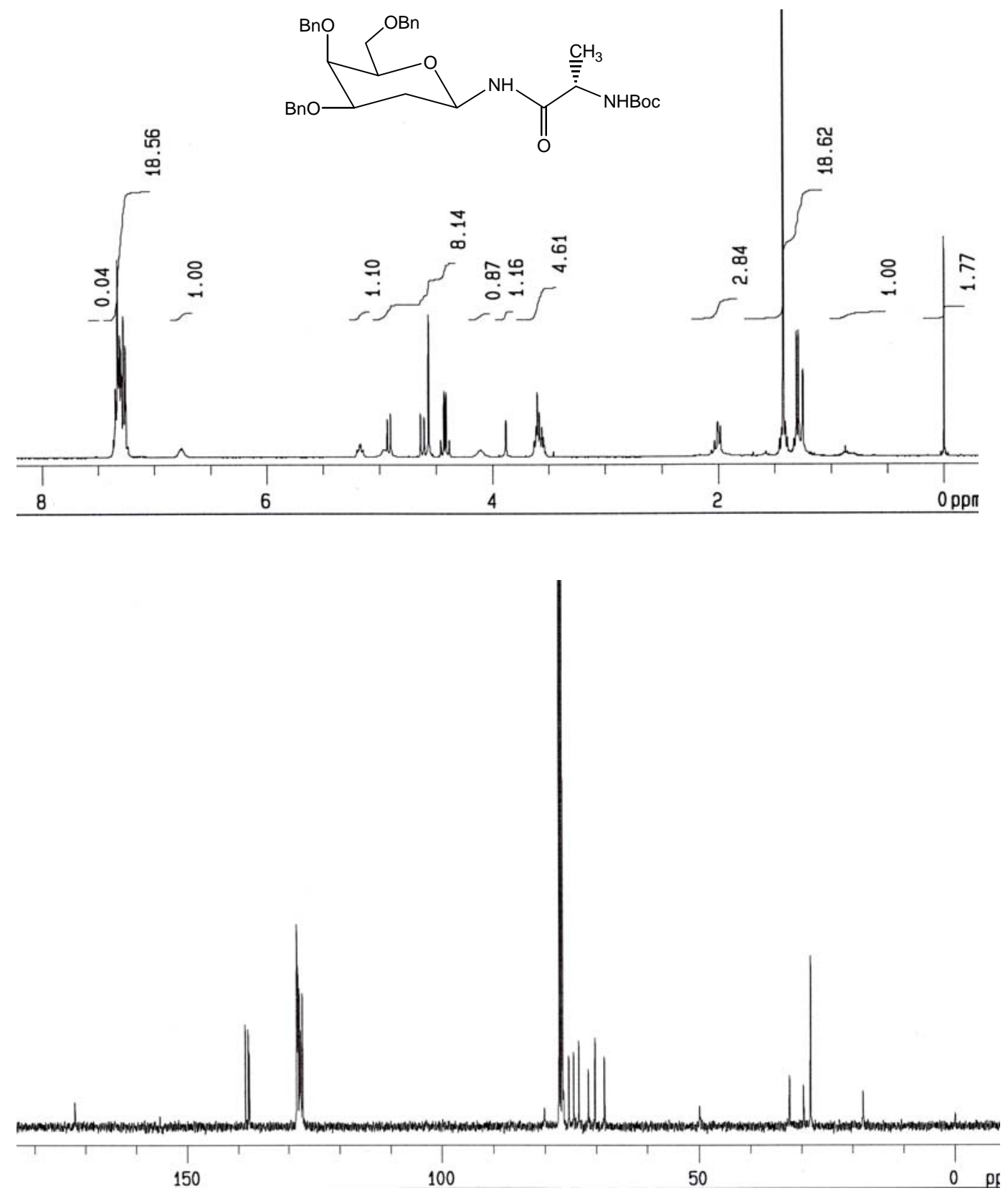
Copy of $1 \mathrm{H}$ and $13 \mathrm{C}$ spectra for compound 36.
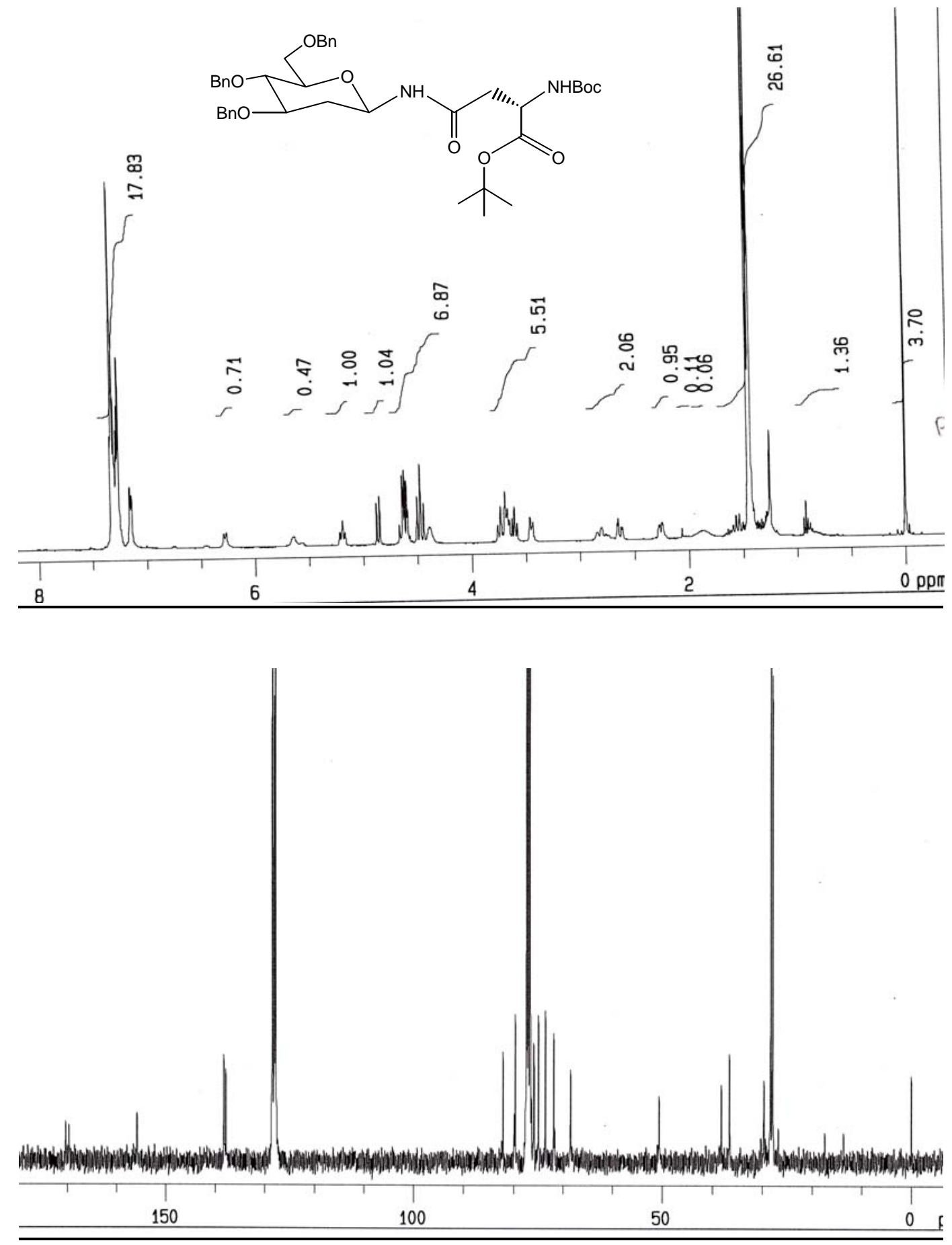


\section{Copy of 1H and 13C spectra for compound 37.}
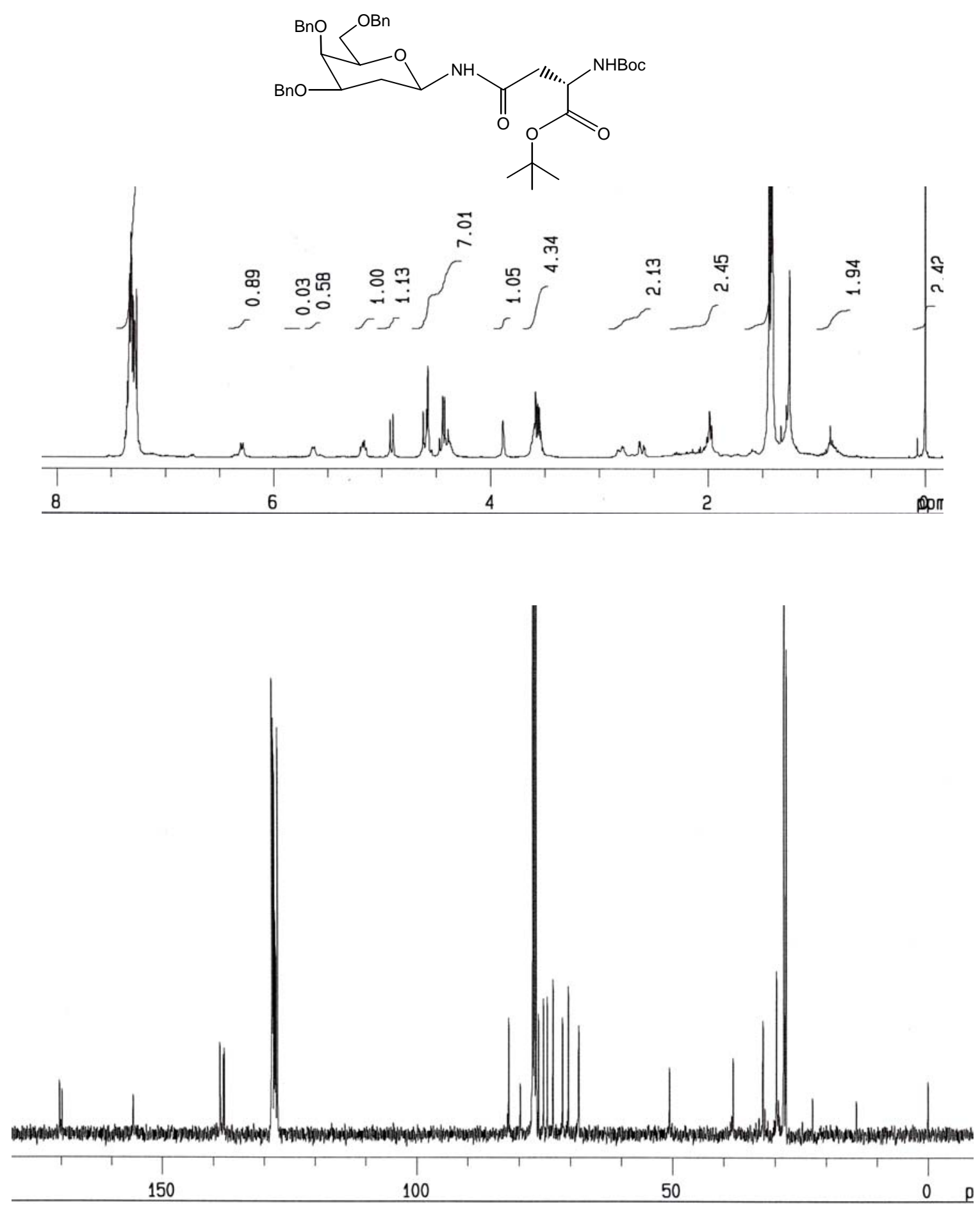